\title{
¿El fortalecimiento de los derechos de propiedad intelectual estimula la innovación? Un análisis exploratorio de la dinámica de patentamiento por sectores industriales en Colombia, 1980-2010*
}

Do intellectual property rights stimulate innovation? An exploratory analysis of the industrial patents' dynamic in Colombia, 1980-2010

O fortalecimento dos direitos de propriedade intelectual estimula a inovação? Uma análise exploratória da dinâmica de patentes por setores industriais em Colômbia, 1980-2010

Mercedes Campi

Universidad de Buenos Aires, Argentina

ORCID: https://orcid.org/0000-0002-2310-7180

Marco Antonio Dueñas Esterling

Universidad Jorge Tadeo Lozano, Colombia

ORCID: https://orcid.org/0000-0002-2327-0818

Julio Cesar Zuluaga ${ }^{\text {a }}$

Pontificia Universidad Javeriana, Colombia

julio.zuluaga@javerianacali.edu.co

ORCID: https://orcid.org/0000-0003-2860-145X
DOI: https://doi.org/10.11144/Javeriana.cao33.fdpi

Recibido: 24 Octubre 2018

Aceptado: 29 Octubre 2020

Publicado: 20 Diciembre 2020

\section{Resumen:}

Este artículo tiene como objetivo explorar el comportamiento de las patentes de residentes y no residentes durante 1980 y 2010. En particular, se analiza cómo este comportamiento podría estar relacionado con el fortalecimiento de la legislación de propiedad intelectual y con el proceso de apertura económica y desindustrialización. La evidencia sugiere que el fortalecimiento de los derechos de propiedad intelectual -DPI- no ha incentivado la innovación local, sino que sólo ha impulsado las solicitudes de patentes de no residentes, en unos pocos campos tecnológicos y por parte de unas pocas empresas multinacionales. En cambio, las empresas nacionales recurren al uso de mecanismos alternativos de propiedad intelectual como los acuerdos de confidencialidad y el secreto industrial para gestionar su conocimiento. Este mecanismo les permite apropiarse de las rentas asociadas a sus esfuerzos en actividades de innovación, caracterizadas por la imitación y adaptación de tecnologías extranjeras. Esta evidencia permite discutir la política de fortalecimiento de los DPI y el estímulo de las patentes de invención como mecanismo para incentivar la innovación en Colombia.

Códigos JEL: 031, 034.

Palabras clave: Patentes, propiedad intelectual, innovación.

\section{Abstract:}

This paper aims to explore the behavior of resident and non-resident patents during 1980 and 2010. In particular, it shows how this behavior could be related to the strengthening of intellectual property legislation and the process of economic liberalization and de-industrialization. The evidence suggests that Intellectual Property Rights -IPRs- have not incentivized local innovation but has only boosted patent applications from non-residents, owned by a few multinational companies in some technological fields. Instead, firms resort to the use of alternative intellectual property mechanisms such as confidentiality agreements and industrial secrecy. This mechanism allows them to manage their knowledge and appropriate the rents associated with their innovation efforts, which are characterized by the imitation and adaptation of foreign technologies. This evidence allows us to discuss the policy of strengthening IPRs and the incentives of invention patents as a mechanism to encourage innovation in Colombia.

JEL Codes: 031, 034.

Keywords: Patents, intellectual property, innovation.

Notas de autor

${ }^{a}$ Autor de correspondencia. Correo electrónico: julio.zuluaga@javerianacali.edu.co 


\section{Resumo:}

Este artigo tem como objetivo explorar o comportamento das patentes de residentes e não residentes durante 1980 e 2010 . Em particular, analisa-se como este comportamento poderia estar relacionado com o fortalecimento da legislação de propriedade intelectual e com o processo de apertura econômica e desindustrialização. A evidência sugere que o fortalecimento dos direitos de propriedade intelectual -DPI- não tem incentivado a inovação local, mas apenas tem impulsado as solicitudes de patentes de não residentes, em poucos campos tecnológicos e por parte de umas poucas empresas multinacionais. Entretanto, as empresas nacionais recorrem ao uso de mecanismos alternativos de propriedade intelectual como os acordos de confidencialidade e o segredo industrial para gerir seu conhecimento. Este mecanismo lhes permite se apropriar das rendas associadas a seus esforços em atividades de inovação, caracterizadas pela imitação e adaptação de tecnologias estrangeiras. Esta evidência permite discutir a política de fortalecimento dos DPI e o estímulo das patentes de invenção como mecanismo para incentivar a inovação em Colômbia.

Códigos JEL: 031, 034.

Palavras-chave: Patentes, propriedade intelectual, inovação.

\section{Introducción}

Los estudios de economía de la innovación han destacado la importancia de la propiedad intelectual PI- como instrumento de política pública para el estímulo de la innovación. De un lado, la literatura ha planteado que el fortalecimiento de los derechos de propiedad intelectual -DPI- en un país podría aumentar la innovación, lo que se reflejaría por ejemplo en un aumento de las patentes solicitadas por residentes. Además, podría generar un aumento de la transferencia de tecnología a través de la inversión extranjera directa -IED-, el comercio internacional o el licenciamiento de tecnología, lo cual podría reflejarse en un aumento de las solicitudes de patentes por parte de no residentes.

Sin embargo, trabajos clásicos (Mansfield, 1986; Deardorff, 1992) y recientes (Bessen \& Maskin, 2009; Henry \& Stiglitz, 2010; Campi \& Dueñas, 2019) plantean que los sistemas actuales de DPI pueden impedir tanto la innovación como la difusión, afectando especialmente a los países en desarrollo. En este marco, un aumento de las patentes no necesariamente implica un aumento de las actividades de innovación ni de la transferencia de tecnología dado que la relación entre sistemas fuertes de DPI e innovación no es lineal ni necesariamente positiva. Varios autores han demostrado que el fortalecimiento de los DPI puede generar un incremento en el patentamiento no necesariamente asociado a una mayor innovación sino, por ejemplo, a cambios en las estrategias de captura de rentas de las empresas (Boldrin \& Levine, 2008). Al mismo tiempo, autores como Sweet y Maggio (2015) muestran que los sistemas más fuertes de protección de la PI incentivan la innovación, pero sólo lo hacen cuando los países parten de un cierto nivel de complejidad de su producción y de desarrollo, por lo que es posible esperar que procesos de desindustrialización puedan afectar los efectos positivos que predice la teoría.

El objetivo de este artículo es explorar empíricamente este debate sobre la relación entre el fortalecimiento de los DPI, el proceso de desindustrialización y el comportamiento de patentes de residentes y no residentes en Colombia para el período 1980-2010. Con base en información de aplicación de patentes de PATSTAT se pretende responder si los cambios en la legislación y los índices de protección de DPI generaron un incremento en la actividad de patentamiento y si existen diferencias sectoriales en este proceso. Además, se analiza cómo el proceso de desindustrialización y de incentivos a flujos de inversión extranjera puede haber afectado el comportamiento de patentes de residentes y no residentes de manera diferente. En particular, se plantea que el bajo patentamiento de las empresas locales se debe a que estas no recurren a las patentes para proteger y apropiar los resultados de sus actividades de Investigación y Desarrollo. Las actividades de innovación de las empresas colombianas se caracterizan por "formas de innovar" (Malaver \& Vargas, 2013) basadas en la imitación y adaptación de tecnologías extranjeras y por el uso de mecanismos de PI alternativos a las patentes como los modelos de utilidad, el secreto industrial, la alta complejidad en el diseño, el registro de diseños industriales, acuerdos y contratos de confidencialidad, las marcas y signos distintivos.

El análisis del caso colombiano es importante por varias razones. Los sistemas de DPI se han ido fortalecido progresivamente desde la década de 1970, en el marco de diversos procesos de integración regional, y en aras 
de cumplir con requerimientos internacionales, tendiendo hacia la armonización con los sistemas globales de protección de propiedad intelectual. En los años 1994 y 2000, dos reformas terminaron de cumplir con los requerimientos de los estándares requeridos por el acuerdo sobre los Aspectos de los Derechos de Propiedad Intelectual relacionados con el Comercio -ADPIC-, firmado en Marrakech, Marruecos, el 15 de abril de 1994. Asimismo, otra fuerza que ha impulsado el fortalecimiento de los sistemas de DPI ha sido la firma de una serie de acuerdos comerciales que incluyen capítulos con requerimientos relativos a DPI (Campi \& Dueñas, 2019). Por otro lado, la evolución de los sistemas de protección de la PI muestra diferencias sectoriales importantes. En particular, como se demostrará, los DPI para las manufacturas en general y para el sector agrícola se han endurecido más con relación al promedio para los países de Latinoamérica, mientras que el sector de farmacéutica ha sufrido un fortalecimiento inferior al observado para el promedio de los demás países de América Latina. Este contexto particular permite indagar si existe un efecto diferente en las actividades de patentamiento en dichos sectores y si esto además se refleja en un comportamiento diferente para las patentes solicitadas por residentes y no residentes.

Los resultados del análisis exploratorio indican que desde 1980 a 2010 las actividades de patentamiento en Colombia se caracterizan por una elevada participación de no residentes en las solicitudes de patentes y una muy baja participación de residentes en las mismas. Además, las solicitudes de patentes se concentran en unos pocos sectores y unas pocas empresas multinacionales. Esta situación coincidió con una desaceleración del crecimiento de la industria colombiana, iniciado en 1974, que derivó en un proceso de desindustrialización reflejado en baja productividad, creación de empleo, acumulación y modernización de capital, y de cambio tecnológico. Además, este proceso se dio en el marco de una apertura de la economía y eliminación de las restricciones a la inversión extranjera directa (Kalmanovitz, 2011).

Como posible explicación se sostiene que el proceso de desindustrialización colombiana y de apertura a la inversión extranjera que tuvo lugar desde 1974 puede haber afectado el comportamiento de las empresas colombianas con relación al patentamiento. Ambos fenómenos pueden haber impulsado el patentamiento de no residentes y reducido el de residentes, en términos relativos principalmente. Además, el bajo nivel de patentamiento por parte de residentes puede estar relacionado con que las actividades de innovación realizadas por residentes se inclinan hacia la imitación y que estas innovaciones no son aptas para realizar una solicitud de patente. Los datos de las solicitudes de modelos de utilidad muestran que son mayores las de residentes que las solicitudes por parte de no residentes, dado que en Colombia los modelos de utilidad otorgan protección como una patente, pero sin evaluar el nivel o altura inventiva de la creación, debiendo sólo cumplir los requisitos de novedad y aplicación industrial (Mayor, 2005). Por ello se sostiene que los modelos de utilidad y otros mecanismos informales de PI son una forma de protección de la PI más acorde a las actividades de invención y formas de innovar de los países en desarrollo como Colombia, las cuales se basan en buena medida en la copia, adaptación a la realidad local y la mejora de invenciones disponibles a nivel mundial.

Este artículo se estructura en cuatro secciones, además de esta introducción. En la primera sección se presenta la revisión de la literatura. En la segunda sección se presenta la metodología y se reconstruye la evolución de los sistemas e índices de protección de la PI en Colombia y en América Latina. En la tercera sección se analiza la dinámica del patentamiento en Colombia en el contexto de reformas económicas y de desindustrialización de la economía colombiana, además de la evolución de las solicitudes de patentes de no residentes en los principales campos tecnológicos. Finalmente, se presentan las conclusiones generales del estudio. 


\section{Motivación y planteamiento del problema}

Las patentes son un mecanismo de política pública que permite a los inventores obtener un retorno a sus inversiones, por lo que proveen un incentivo ex ante para el avance tecnológico. Sin embargo, al mismo tiempo, la patente permite a su propietario ejercer un poder de monopolio sobre el mercado del nuevo producto, por lo que ex post puede generar un desincentivo a la difusión de tecnologías y en el largo plazo a la innovación.

Esta situación ha generado que la evidencia empírica sobre la relación entre patentes e innovación sea mixta (para ampliar la discusión ver Sweet \& Eterovic, 2019). De un lado existen estudios que han demostrado efectos positivos de la armonización y fortalecimiento de la propiedad intelectual a nivel global. El estudio de Sweet y Maggio (2015) prueba el impacto de sistemas de DPI cada vez más rigurosos en la innovación a través de un índice de complejidad económica de 94 países entre 1965 y 2005. Sus resultados confirman que los sistemas de propiedad intelectual más fuertes generan niveles más altos de complejidad económica. Sin embargo, señalan que sólo los países con un nivel inicial de desarrollo y complejidad superior al promedio disfrutan de este efecto.

Por otro lado, estudios teóricos (Deardorff, 1992; Helpman, 1993) y empíricos (Chaudhuri, Goldberg, \& Jia, 2006) han planteado los posibles efectos negativos sobre la innovación y el bienestar de extender la protección de la PI a los países en desarrollo. Por ejemplo, Deardorff (1992) sostiene que mientras el bienestar del país inventor aumenta con la extensión de la protección de la propiedad intelectual, el de los países en desarrollo decae inclusive en mayor proporción que el incremento en bienestar de los países inventores. Para el caso de la India, Mani (2020) muestra que frente al notable cambio en su régimen de patentes para cumplir con los requerimientos de los ADPIC, ha habido una mejora significativa en las solicitudes y concesiones de patentes. Sin embargo, la mayoría de las solicitudes son realizadas por empresas multinacionales, mientras que la proporción de inventores nacionales se ha mantenido igual o incluso se ha reducido.

Esta evidencia ha llevado a varios autores a sostener que las dinámicas de patentamiento de un país dependen de varios factores como la legislación, las costumbres, la aplicación (enforcement), características específicas de las industrias, o la existencia y uso de otras formas de apropiación de las rentas de innovación. Por ello, países de niveles de desarrollo similares suelen tener dinámicas diferentes en sus actividades de patentamiento, lo que indicaría que la relación entre propiedad intelectual e innovación no es lineal (Papageorgiadis \& Sharma, 2016) y depende de factores como los flujos de inversión extranjera directa y el nivel de desarrollo económico (Campi \& Dueñas, 2019; Kashcheeva, 2013).

Por otro lado, autores como Mansfield (1986) y Cohen, Nelson, y Walsh (2000) sostienen que las empresas normalmente protegen las ganancias derivadas de la invención con una variedad de mecanismos formales e informales, que incluyen no sólo las patentes, sino además el secreto industrial, las ventajas derivadas de ser líder y el uso de capacidades complementarias de comercialización y fabricación. Basados en una encuesta a 1478 laboratorios de I+D en el sector manufacturero de EE. UU encontraron que, de estos mecanismos, las patentes tienden a ser el mecanismo que menos enfatizan las empresas en la mayoría de las industrias manufactureras.

Hall, Helmers, Rogers, \& Sena (2013) muestran que la proporción de empresas en el Reino Unido que patentan -entre las que desarrollan alguna forma de I+D- es de alrededor del $4 \%$. Señalan que esto es mucho más bajo de lo esperado porque los datos indican que alrededor del $20 \%$ de las empresas que realizan I+D informan sobre innovaciones de productos que son "nuevas en el mercado", que en principio podrían ser patentables. Este mismo estudio muestra que las empresas no consideran que las patentes u otras formas de propiedad intelectual registrada sean tan importantes como la propiedad intelectual informal para proteger las invenciones. Los mismos autores señalan como posibles explicaciones de la baja proporción de empresas que patentan, que la mayoría de las empresas son pequeñas, la mayoría de las innovaciones son solo nuevas 
para la empresa y la mayoría de las empresas se encuentran en sectores donde las patentes no se utilizan mucho o donde la actividad innovadora es baja.

En el contexto latinoamericano, varios estudios han analizado el efecto de la armonización de la propiedad intelectual después de las reformas inducidas por la Ronda de Uruguay. Por ejemplo, el trabajo de Mccalman (2001) cuantifica el impacto de la armonización internacional de patentes implícita en el acuerdo ADPIC. Su análisis sugiere que la protección por medio de patentes es un método importante para apropiarse de las rentas de una invención porque tiene la capacidad de generar grandes transferencias de ingresos entre países, siendo Estados Unidos el principal beneficiario, junto con Canadá, Reino Unido y Japón. Según el autor, estas transferencias alteraron significativamente la distribución percibida de los beneficios de la Ronda Uruguay, donde los beneficios de Estados Unidos se mejoraron sustancialmente, mientras que los de los países en desarrollo disminuyeron considerablemente. Sin embargo, plantea que es importante hacer más investigaciones que evalúen si existen posibles ganancias para los países en desarrollo de eficiencias derivadas de estos acuerdos, de manera que se compensen los impactos negativos de estas transferencias.

Para el caso colombiano, el estudio de Forero-Pineda, Laureiro-Martínez \& Marín (2011) analiza empíricamente la relación entre la PI y los patrones de innovación de las empresas pequeñas y medianas del sector manufacturero. Su conclusión principal es que las empresas propietarias de patentes tienen una tasa significativamente menor de productos nuevos que se introducen en el mercado. Sus resultados ofrecen evidencia empírica que las empresas propietarias de patentes son menos innovadoras en términos de nuevos productos, y en relación con sus esfuerzos de innovación (medidos por gasto en $\mathrm{I}+\mathrm{D}+\mathrm{i}$ ). Esto respalda la hipótesis de que las patentes eximen a sus titulares de la necesidad de seguir un proceso continuo de innovación.

Frente a este debate en la literatura, este estudio pretende aportar nueva evidencia empírica para el caso colombiano que evalúe la relación entre propiedad intelectual e innovación. Esta evidencia mixta sobre los posibles efectos positivos o negativos nos lleva a preguntarnos en qué medida en el caso colombiano la armonización y fortalecimiento de los DPI ha estimulado la innovación. Para abordar este problema a continuación se plantea un estudio exploratorio donde a partir de evidencia y narrativa histórica se reconstruye la evolución de los DPI en el país y se analiza el comportamiento del patentamiento de residentes y no residentes.

\section{Metodología y la evolución de la protección de la PI en Colombia}

Este estudio exploratorio emplea datos de solicitudes de patentes en Colombia para el período 1980-2010 con el fin de analizar la dinámica del patentamiento de residentes y no residentes. Se utilizan datos de PATSTAT ${ }^{1}$ de solicitudes de patentes ya que, al existir demoras en la evaluación y otorgamiento de patentes, los datos de patentes concedidas son menos confiables y pueden estar sesgados. La actividad de patentamiento se analiza en el contexto de desindustrialización de la economía colombiana desde 1974 y de las reformas económicas tendientes a la liberalización financiera y de los mercados de capitales junto a la apertura económica y comercial que se iniciaron en la década de 1990.

Además, para comparar la evolución de los DPI se utilizó información histórica sobre la legislación colombiana y se analizan tres índices que estudian detalladamente la evolución de la legislación en cada país, identificando los rasgos clave que caracterizan las diferencias de los sistemas de DPI en América Latina y que permiten transformar estas disposiciones legislativas en indicadores cuantitativos.

La protección de la PI en Colombia comenzó a asumir características similares a los sistemas internacionales a mediados del siglo XX, aunque la protección fue más débil que el promedio de los países de América Latina. Pese a que ha ido aumentando a lo largo de los años, fue a partir de diversas negociaciones en el marco de un 
proceso de integración regional y principalmente de la firma de los ADPIC hacia la década de 1990, cuando comenzó a aumentarse notablemente la protección de la PI (Park, 2008; Campi \& Nuvolari, 2020).

A partir de esta década los sistemas de protección de la propiedad intelectual se vieron afectados a lo largo de los años analizados por tres fenómenos principalmente: el primero tiene que ver con la participación de Colombia en el proceso de integración regional de los países del Pacto Andino y posteriormente de la Comunidad Andina -CAN-2 ${ }^{2}$, así como en la Asociación Latinoamericana de Libre Comercio -ALALC-, posteriormente devenida en la Asociación Latinoamericana de Integración -ALADI- ${ }^{3}$ y los intentos de armonización de las legislaciones de DPI de los países miembros. El segundo se deriva de la entrada a la OMC y la consecuente adhesión a los ADPIC; y el tercero, de la firma de acuerdos comerciales de diferentes tipos que incluyen capítulos relativos a los sistemas de DPI.

\section{Cambios en la legislación sobre derechos de propiedad intelectual en Colombia}

En 1971 se promulgó la ley de propiedad industrial por medio del Decreto Ley 410 que reglamentó el Código de Comercio. A partir de esta reforma se distinguieron los DPI en nuevas creaciones (que incluye las patentes de invención y los modelos y dibujos industriales) y signos distintivos (que incluye las marcas). Esta reforma además cambió los requisitos para la concesión de patentes, los cuales pasaron a incluir novedad, altura inventiva y aplicación industrial, en línea con los requisitos de la mayoría de los países. Además, se discutió el alcance de la protección de las patentes y se determinó su duración hasta 12 años.

Desde esta última reforma, la legislación de Colombia en DPI comenzó a acercarse a una armonización con la legislación internacional, proceso que comenzó en el marco de la integración regional. Hacia 1970, la entonces Asociación Latinoamericana de Libre Comercio -ALALC - se propuso diseñar un nuevo esquema de integración de la región con el objetivo de sentar las bases de lo que sería la integración comercial y jurídica de los países miembros.

En paralelo, en el marco del Pacto Andino comenzó a discutirse la conveniencia de establecer un régimen común que regulara las diversas actividades relacionadas con cada uno de los nuevos pilares de la integración, entre ellos la propiedad industrial, el arancel externo común y el régimen común de capitales extranjeros, marcas, patentes, licencias y regalías. Es así como se creó el Acuerdo de Integración Subregional conocido como Acuerdo de Cartagena, el cual incluyó un capítulo con el mismo nombre y que conserva en la actualidad varias de sus disposiciones originales. En dicho capítulo se plantea regular la "armonización de las políticas económicas y coordinación de los planes de desarrollo". En efecto, este régimen fue aprobado el 31 de diciembre de 1970, mediante la "Decisión 24" de la Comisión del Acuerdo de Cartagena que dispuso que "la Comisión, a propuesta de la Junta, adoptará un reglamento para la aplicación de las normas sobre propiedad industrial". Durante los cuatro años siguientes - en cumplimiento del citado mandato- los órganos del Acuerdo llevaron a cabo los trabajos para la discusión y elaboración de lo que constituiría el régimen común de propiedad industrial, el cual se aprobaría el 5 de junio de 1974 conocido como la "Decisión 85" y con la denominación de "Reglamento para la aplicación de las normas sobre propiedad industrial".5

Esta decisión estableció disposiciones sobre los siguientes capítulos: el primero trataba sobre las patentes de invención y comprendía varias secciones sobre los requisitos de patentabilidad, los titulares de la patente, las solicitudes, los trámites, los derechos conferidos por la patente, las obligaciones del titular, el régimen de licencias, la protección legal y la nulidad de la patente. El capítulo segundo se refería a los dibujos y modelos industriales; el tercero, a las marcas, los requisitos para el registro, el procedimiento, los derechos conferidos por el registro, la cesión y trasmisión de los mismos. El capítulo cuarto incluía las denominadas disposiciones 
varias. Estas disposiciones se asemejaban en muchos aspectos a los lineamientos que establecería el Acuerdo sobre los ADPIC. ${ }^{6}$

Aunque la "Decisión 85" tuvo una vigencia relativamente larga (fue sustituida a inicios de 1990), su aplicación fue parcial y limitada debido a que su alcance se aplicó en sólo tres de los cinco Países Miembros del Acuerdo de Cartagena (Colombia, Ecuador y Perú) y su cumplimiento no fue desarrollado. Esto llevó a que fuera inicialmente sustituida por la "Decisión 311" el 12 de diciembre de 1991. ${ }^{7}$ Estas primeras Decisiones, la 85 y la 311, tuvieron una limitada aplicación o una vida jurídica corta debido a las presiones internas y externas sobre los negociadores gubernamentales y a los complejos intereses de adoptar o configurar una norma comunitaria que por su propia naturaleza debe ser diferente a los intereses estrictamente nacionales o particulares. Esto significó que el régimen común proyectado desde el Pacto Andino, inicialmente concebido bajo el principio de reglamento, fuera incumplido e inestable.

Este problema comenzó a resolverse con la creación de la "Decisión 344" vigente para los países del Pacto desde el $1^{\circ}$ de enero de 1994, firmada el 29 de octubre de $1993 .{ }^{8}$ Dicho acuerdo implicó varios cambios importantes en los estándares y nivel de protección de la PI de los países y acercó la legislación colombiana a la legislación internacional. La Decisión 344 comenzó a regir y ser aplicada de manera efectiva en cada uno de los países miembros del Pacto, además que avanzó y amplió los capítulos desarrollados en la “Decisión 85” al incluir un capítulo referente a los modelos de utilidad, e incorporar otro relacionado con los lemas y nombres comerciales. Sin embargo, la Decisión 344 no implicó que todos los países tuvieran exactamente la misma regulación sobre todas las áreas en temas de PI debido a que dejó espacio a cierta flexibilidad del régimen común que permitió a cada país establecer regulaciones propias para determinadas materias.

En Colombia hubo importantes cambios en la legislación que venía aplicándose en el tema de patentes. En primer lugar, se estableció una clara definición y distinción entre patente de invención, modelos de utilidad, diseño industrial y secreto industrial, lo cual afectó, a su vez, los requisitos para las invenciones. Por ejemplo, la patente de invención se definió como un título a través del cual el Estado confería a su titular el derecho de impedir que terceros, sin su consentimiento, explotaran la invención patentada. En cuanto a los requisitos para patentar un invento se determinó que debían cumplirse los requisitos de novedad, nivel inventivo y aplicabilidad industrial. Así, la novedad se determinaba cuando una posible invención no hacía parte del estado previo de la tecnología y/o no había sido conocido públicamente en algún lugar del mundo. En cuanto al nivel o tipo de invención se establecía determinando que la invención no era el resultado de variación o adaptación de una tecnología previamente existente y, finalmente, debía cumplir el requisito de que dicha innovación fuera susceptible de ser usada o aplicada a una industria en particular.

\section{Los acuerdos internacionales y el fortalecimiento de los derechos de propiedad intelectual}

De manera paralela a las decisiones del Acuerdo de Cartagena, los acuerdos internacionales, originados en el seno de la Organización Mundial de Comercio -OMC-, también influyeron la legislación colombiana en el tema de patentes, bajo el desarrollo de dos procesos que fueron casi simultáneos. En primer lugar, a través de la legislación que emanaba de los acuerdos de los países del Pacto Andino, en el año 2000 se firmó la "Decisión 486” que reemplazó a la 344. Básicamente, con esta decisión se intentó actualizar la legislación del Pacto con los estándares desarrollados por los ADPIC, al hacer modificaciones al régimen común sobre propiedad industrial en temas que se relacionaban con el trato nacional, la nación más favorecida, la preservación del patrimonio biológico y de los conocimientos tradicionales, al igual que la concesión de patentes de invención en todos los campos tecnológicos. Sin embargo, como fuera mencionado, la Decisión 344 ya contenía estándares mínimos en materia de protección de la PI contenidos en los ADPIC (Frankel, 2011). 
En segundo lugar, un proceso paralelo que ha tendido a fortalecer y a armonizar la protección de la PI en Colombia y a incorporar nuevas modificaciones al derecho interno se deriva de la firma de acuerdos comerciales de diversos tipos (bilaterales, regionales o multilaterales) que incluyen capítulos sobre aspectos vinculados a los DPI. En años recientes, como parte de un proceso general a nivel mundial, los acuerdos comerciales incluyen además de las cuestiones relacionadas con el comercio, otras cuestiones extracomerciales, entre las cuales se encuentran proposiciones relacionadas con los DPI (Dür, Baccini, \& Elsig, 2014; Kohl, Brakman, \& Garretsen, 2016; Campi \& Dueñas, 2019; Hofmann, Osnago, \& Ruta, 2017). Así, desde mediados de la década de 1990, Colombia firmó diversos acuerdos comerciales que incluyen no solamente reducciones arancelarias u otras cuestiones comerciales, sino también capítulos o disposiciones que implican, en muchos casos, modificaciones de algunos aspectos de los sistemas de DPI, como se muestra en la tabla 1.

TABLA 1

Acuerdos comerciales vigentes en Colombia que contienen disposiciones sobre derechos de propiedad intelectual

\begin{tabular}{|l|l|c|c|}
\hline \multicolumn{1}{|c|}{ Acuerdo } & \multicolumn{1}{|c|}{ Tipo } & $\begin{array}{c}\text { Fecha de } \\
\text { firma }\end{array}$ & $\begin{array}{c}\text { Fecha de entrada } \\
\text { en vigor }\end{array}$ \\
\hline Colombia, México y Venezuela & Preferencial de comercio & $13-06-94$ & $01-01-95$ \\
\hline OMC & Multilateral & $30-04-95$ & $30-04-95$ \\
\hline $\begin{array}{l}\text { MERCOSUR - Colombia y } \\
\text { Ecuador }\end{array}$ & Preferencial de comercio & $18-10-04$ & $01-02-05$ \\
\hline Estados Unidos - Colombia & Acuerdo de libre comercio & $22-11-06$ & $15-05-12$ \\
\hline EFTA- Colombia & Acuerdo de libre comercio & $25-11-08$ & $07-01-10$ \\
\hline Unión Europea - Colombia y Perú & Acuerdo de libre comercio & $26-06-12$ & $01-08-13$ \\
\hline República de Corea - Colombia & Acuerdo de libre comercio & $21-02-13$ & $15-07-16$ \\
\hline Costa Rica - Colombia & Acuerdo de libre comercio & $22-05-13$ & $01-08-16$ \\
\hline Alianza del Pacifico & Acuerdo de libre comercio & $10-02-14$ & $01-05-16$ \\
\hline Panamá-Colombia & Acuerdo de libre comercio & $20-09-13$ & no entró en vigor \\
\hline Israel- Colombia & Acuerdo de libre comercio & $30-09-13$ & no entró en vigor \\
\hline MERCOSUR-Colombia & $\begin{array}{l}\text { Acuerdo de asociación } \\
\text { económica }\end{array}$ & $21-07-17$ & $11-06-18$ \\
\hline
\end{tabular}

Fuente: elaboración propia con datos de http://www.tlc.gov.co

En general, estos acuerdos comprometen a los países firmantes a suscribir a diversos tratados internacionales y a modificar sus legislaciones para adecuarlas a dichos tratados o a demandas específicas relacionadas con DPI, pudiendo incluir recomendaciones, así como también disposiciones legalmente aplicables, las cuales deben ser implementadas para cumplir con lo acordado y aprovechar los aspectos relacionados con el comercio. Además, en estos acuerdos se explicita que las partes signatarias pueden -aunque no están obligadas- establecer en su legislación una protección y observancia más amplia de los DPI que la requerida en los acuerdos, siempre que esa protección más amplia no contravenga las disposiciones del mismo.

Por lo tanto, la firma de acuerdos comerciales con capítulos de DPI tendió a reforzar y a armonizar aún más los sistemas de DPI a nivel internacional. Dado que exigían estándares más altos de protección de la PI que los exigidos por los ADPIC, se conocen en la literatura como ADPIC+ o ADPIC-Plus, los cuales incluyen nuevas áreas de DPI, como la patente de formas de vida o derechos de autor que se aplican a contenido electrónico, la implementación de niveles más amplios o estándares de protección de PI que el exigido por los ADPIC, la adopción de nuevos convenios no incluidos en otros acuerdos internacionales o la eliminación de flexibilidades disponibles en los ADPIC (Mercurio, 2006; Biadgleng \& Maur, 2011).

La firma de acuerdos comerciales con disposiciones sobre DPI conllevó en muchos casos reformas significativas que además redujeron la posibilidad de diseñar sistemas de DPI adecuados a las estructuras productivas propias, además de eliminar flexibilidades que están contempladas en los APDIC. Biadgleng y Maur (2011) mostraron que la implementación real de las obligaciones relacionadas con DPI en los acuerdos comerciales a menudo requiere una revisión relativamente extensa de la legislación, las regulaciones y las 
prácticas. De este modo, los acuerdos comerciales con capítulos de DPI son claros impulsores de reformas significativas y su implementación creó un desafío real y complejo para los países en desarrollo (Campi et al., 2017).

\section{Indicadores de la protección de la propiedad intelectual}

La dinámica reciente de la evolución de la protección de la PI en Colombia puede observarse de forma comparativa a través de índices que cuantifican para diferentes países los niveles de protección. A pesar del reciente proceso de armonización de los sistemas de DPI, aún existe heterogeneidad en los niveles y formas de protección que adoptan los países, dada la libertad que cada país posee para diseñar sus sistemas siempre que cumplan con los requerimientos mínimos de los ADPIC. Por lo tanto, los indicadores cuantitativos de DPI pueden contribuir a ofrecer una caracterización de la situación de cada país y proporcionar evidencia para realizar comparaciones entre países y a lo largo del tiempo.

Para analizar el caso de Colombia, se utilizan tres índices que estudian detalladamente la evolución histórica de la legislación del país, identificando los rasgos clave que caracterizan las diferencias de los sistemas de DPI y transforman estas disposiciones legislativas en indicadores cuantitativos. Estos índices consideran elementos comunes de las legislaciones relacionadas con los DPI de los países pero que tienden a mostrar diferencias entre los mismos y le asignan un valor, permitiendo obtener indicadores cuantitativos y comparativos.

El índice de protección a través de patentes de Ginarte y Park (1997) y Park (2008) es un indicador de la protección disponible para la industria y está compuesto por cinco elementos: i) alcance de la cobertura, ii) membresía en acuerdos internacionales de patentes, iii) provisiones sobre la pérdida de protección, iv) mecanismos de aplicación, y v) duración de la protección. Este índice toma valores entre 0 y 5 , siendo 5 el valor que indica una mayor protección.

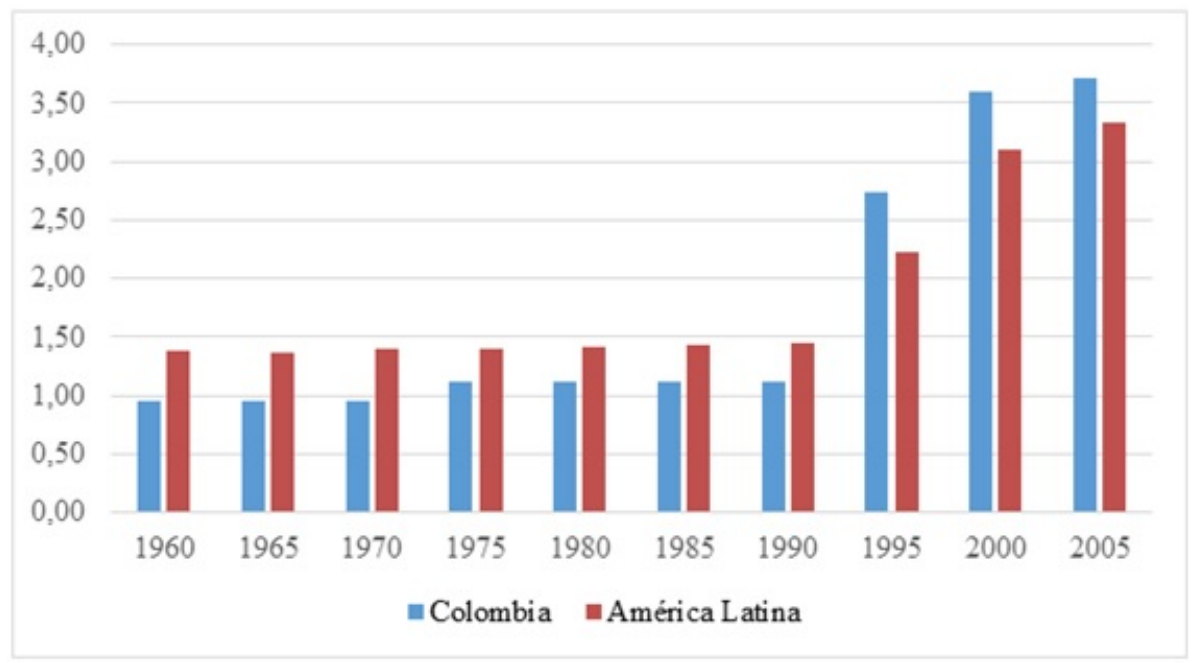

FIGURA 1

Índice de protección de patentes. Colombia y promedio para América Latina, 1960-2005 Fuente: elaboración propia con base en datos de Ginarte y Park (1997) y Park (2008).

La figura 1 muestra la evolución del índice el cual pone de manifiesto que Colombia tuvo una protección más débil que el promedio de América Latina hasta 1995, cuando comenzó a superar el promedio. Esto refleja el cambio de la legislación relativa a patentes de la Decisión 344 y, posteriormente, de la Decisión 486 de 2000.

Una tendencia similar se observa en el caso de la evolución de la propiedad intelectual específica para el caso de la agricultura de Campi y Nuvolari (2015). Este índice se compone de cinco elementos: i) ratificación 
de los convenios de la UPOV, ii) excepción de los agricultores, iii) excepción del obtentor, iv) duración de la protección, y v) alcance de patentes en sectores relacionados con la agricultura (alimentos, plantas y animales, microorganismos, productos farmacéuticos, variedades vegetales). Al igual que el índice de Ginarte y Park (1998), este índice toma valores entre 0 y 5 , siendo 5 el valor que indica una mayor protección. Ver figura 2.

También en el caso de la agricultura, Colombia ha tenido a lo largo de las décadas un sistema de protección más débil que el promedio de los países de América Latina, pero a partir de 1995 el valor del índice para Colombia es superior al del promedio de América Latina, situación que se mantiene hasta el año 2010, siendo la diferencia mucho más notable que en el caso de patentes para manufacturas.

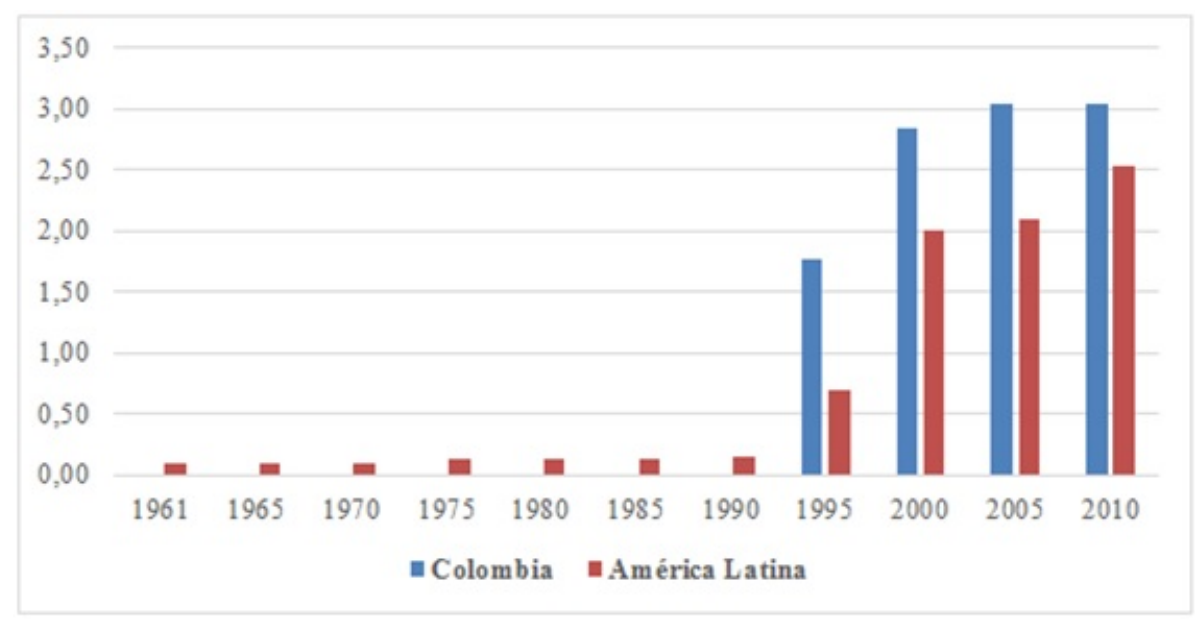

FIGURA 2

Índice de protección de la propiedad intelectual en agricultura.

Colombia y promedio para América Latina, 1961-2010

Fuente: elaboración propia con datos de Campi y Nuvolari (2015).

Por su parte, el índice de protección de la PI específico para el sector farmacéutico de Liu y La Croix (2015) es una agregación de tres subíndices: i) el índice de patentes farmacéuticas que mide la presencia de cinco tipos de patentes y las disposiciones de exclusividad de comercialización que brindan protección para diferentes tipos de invenciones farmacéuticas; ii) el índice de acuerdos internacionales de patentes farmacéuticas que agrega la membresía de un país en tres acuerdos internacionales que extienden la protección de patentes a los inventores extranjeros; y iii) el índice de aplicación de patentes farmacéuticas que agrega medidas estatutarias que mejoran o disminuyen la aplicación pública y privada de los derechos de patente.

En el caso del índice de protección de la PI en el sector de la farmacéutica se observa una tendencia diferente a la del sector agrícola. Colombia otorgaba una protección superior al promedio de América Latina entre 1960 y 1995, mientras que el índice muestra valores algo inferiores al promedio desde el año 2000 . Ver figura 3. 


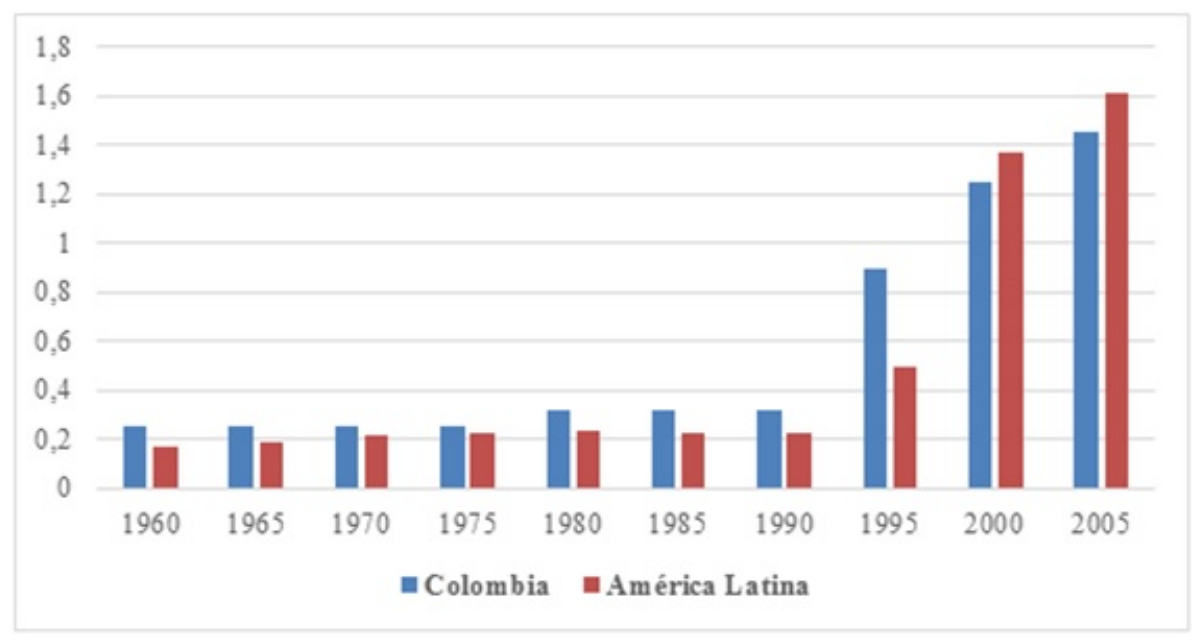

FIGURA 3

Índice de protección de la propiedad intelectual en la industria farmacéutica. Colombia y promedio para América Latina, 1960-2005 Fuente: elaboración propia con datos de Liu y La Croix (2015).

En síntesis, la evolución de los diferentes índices de protección de PI analizados muestra claramente un cambio en la tendencia de los sistemas vigentes a partir de la firma de los ADPIC, tanto para el promedio de Colombia como para América Latina en conjunto. En la siguiente sección se analiza, para el mismo período, cómo han evolucionado las solicitudes de patentes en el marco del sistema de protección de la PI en línea con los estándares internacionales y considerando el contexto en el cual tuvieron lugar las actividades de innovación.

\section{Análisis histórico del comportamiento de las patentes en Colombia en un contexto de reformas y desindustrialización}

\section{Apertura económica y desindustrialización}

Desde 1974 y hasta el final del siglo XX, la industria colombiana inició un proceso de desaceleración de su crecimiento que derivó en una pérdida relativa de peso de las actividades manufactureras en el producto bruto interno, con una notable menor creación de plantas industriales en comparación a la tendencia observada en las décadas anteriores, además de menor generación de empleo y de valor agregado (Echavarría \& Villamizar, 2007; Ortiz, Uribe, \& Vivas, 2009; Brando, 2019). Este proceso de desindustrialización se reflejó en diferentes indicadores como baja productividad, baja acumulación y modernización de capital, escasa ampliación de la capacidad instalada, y consecuentemente, bajo cambio tecnológico (Moreno, 2015). Por ejemplo, el porcentaje de valor agregado de la industria en el PIB de Colombia no sólo ha estado por debajo del promedio latinoamericano, sino que presentó una fuerte caída a partir de la década de 1990. Ver figura 4. 


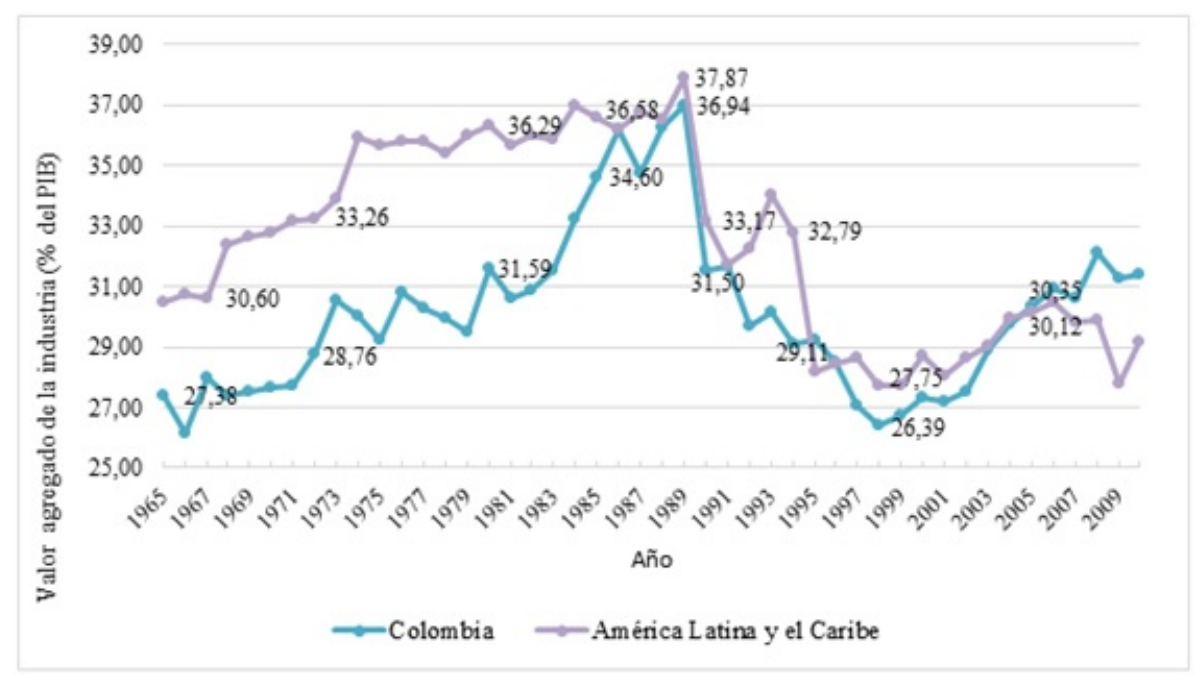

FIGURA 4

Participación del valor agregado de la industria en el PIB de Colombia, 1965-2010 Fuente: Banco Mundial.

Asimismo, la desindustrialización se agudizó con la expansión de la minería y la producción de petróleo que llevaron a una revaluación sostenida de la tasa de cambio real, la cual pudo haber afectado más la competitividad de la industria que la propia apertura o las condiciones de mercado a las que tuvo que someterse (Brando, 2019). La figura 5 muestra la participación de la industria y de la minería en el producto bruto interno entre 1970 y 2010.

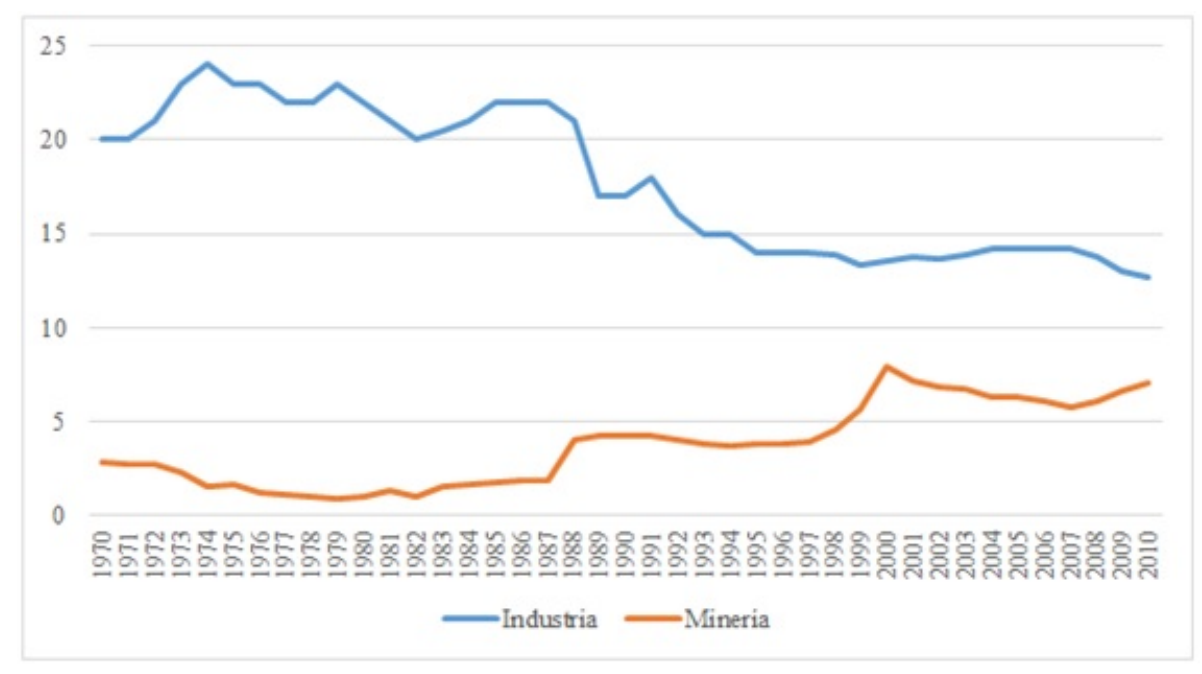

FIGURA 5

Participación de la industria manufacturera y de la minería en el PBI de Colombia, 1970-2010 Fuente: Brando (2019).

El peso de la producción industrial en el PIB alcanzó su máximo histórico en el año 1974, llegando al 24\%. A partir de entonces, la participación disminuyó hasta el 20\% en 1982, y de forma precipitada en la década siguiente, hasta alcanzar un $14 \%$ en 1994 y 13,3\% en 1999. La industria logró repuntar levemente su participación entre los años 2000 y 2007 hasta alrededor del 14\%, pero la crisis internacional de 2008 inició un nuevo proceso de pérdida de participación. Actualmente, la industria contribuye con alrededor del 11\% de la producción al PIB. Por su parte, la minería que empezó con una participación de 2,8\% en 1970, redujo su participación a lo largo de la década hasta llegar a un 0,9\% en 1979, recuperó su participación durante la 
década del 80 hasta llegar a 1,9\% en 1987 y sufrió un salto abrupto a partir de 1988 cuando la participación trepa al 4\%, manteniéndose alrededor de dicho porcentaje durante los años 90 , hasta que nuevamente muestra un salto que la sitúa en 7,94\% en el año 2000. Entre el 2001 y el 2010 su participación promedio es de 6,5\%.

Si bien la economía colombiana había sido relativamente cerrada durante la mayor parte del siglo XX, el proceso de apertura iniciado en los años 70, se agudizó en la década de 1990, con mayor apertura comercial y en su flujo de capitales, lo cual contribuyó a aumentar sus tasas de crecimiento económico. Pero indudablemente el proceso de apertura añadió mayor vulnerabilidad de la economía al ciclo económico internacional, viéndose fuertemente afectada por crisis financieras entre 1998 y 2002, y nuevamente por la crisis financiera de 2008 (Kalmanovitz, 2011). Por otro lado, en los años 90 se implementaron medidas para liberalizar los mercados financieros y de capitales a través de reformas internas. Además, se eliminaron las restricciones a la inversión extranjera directa, a través del establecimiento del tratamiento nacional a las empresas extranjeras, la eliminación de límites a las transferencias de beneficios al exterior, y la reducción de los requerimientos burocráticos para la aprobación de proyectos de inversión (Eslava, Haltiwanger, Kugler, \& Kugler, 2004). Esto aumentó los flujos de IED, los cuales registraron aumentos superiores, en términos relativos, a los que caracterizan al agregado mundial de los flujos de IED, que se presentan por olas, como se observa en la figura 6.

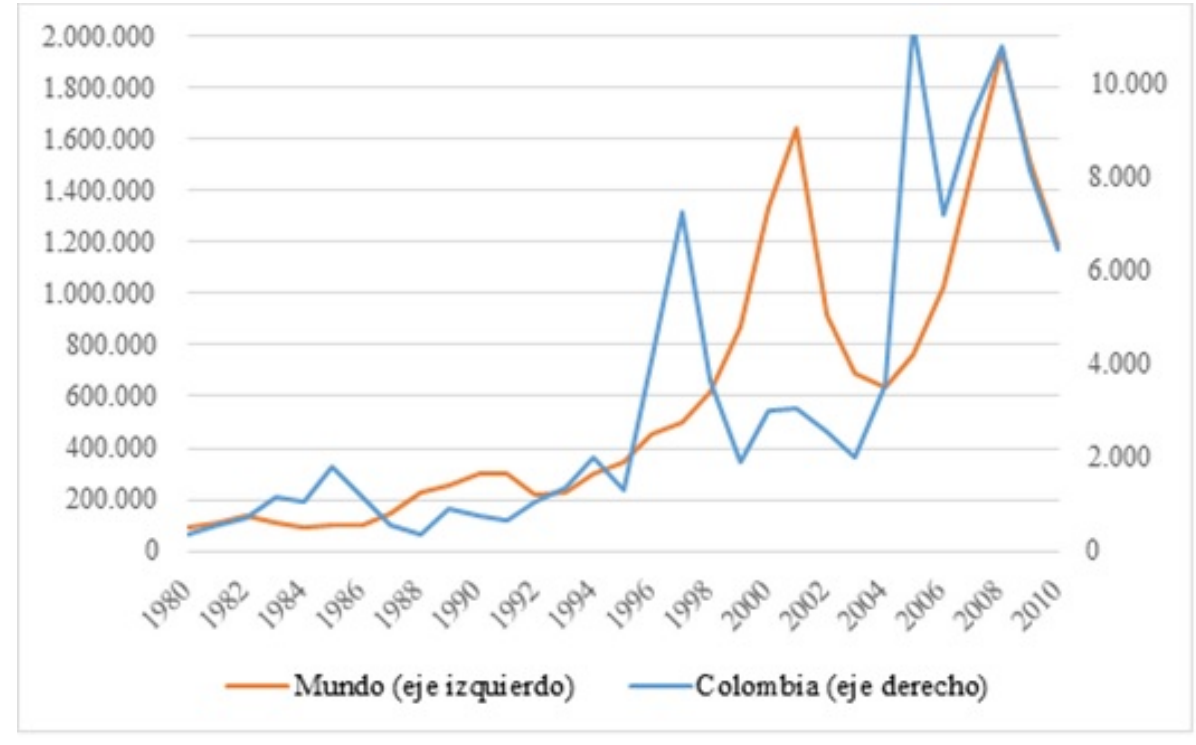

FIGURA 6

Evolución de los flujos de ingreso de inversión extranjera directa (IED). Total del mundo y Colombia. 1980-2010 (en millones de dólares constantes 2010) Fuente: UNCTAD Stats: http://unctadstat.unctad.org

Lo particular del proceso de desindustrialización colombiano es que, en comparación con otras economías en desarrollo, comenzó tempranamente sin haber completado un desarrollo industrial, ni haber alcanzado niveles internacionales de productividad, sin haber desarrollado un sistema tecnológico e industrial competitivo, ni contar con empresas industriales líderes mundiales (Brando, 2019).

La producción industrial, además, se encuentra concentrada en algunos pocos sectores. La tabla 2 muestra la evolución de la participación de las ventas de diferentes sectores industriales en las ventas totales de la industria. La principal actividad manufacturera es la de alimentos, bebidas y tabaco, seguida por la de productos químicos, petrolíferos, carbón, caucho y plástico. Ambos sectores suman más del $50 \%$ del total de las ventas de la industria manufacturera colombiana, superando el 60\% en el año 2010. Le siguen la industria textil, con una participación significativa (de entre el 25 y el 28\%), la fabricación de productos metálicos, maquinaria y equipos (entre el 6 y el 9\%) y la fabricación de productos minerales no metálicos (entre el 3 y 
el 4\%). El resto de los sectores tiene una participación menor al 3\%. A lo largo del período, la participación de los diferentes sectores es relativamente estable.

TABLA 2

Evolución de la participación de diferentes sectores industriales en las ventas totales (En porcentajes)

\begin{tabular}{|l|c|c|c|c|}
\hline Sector & $\mathbf{1 9 9 5}$ & $\mathbf{2 0 0 0}$ & $\mathbf{2 0 0 5}$ & $\mathbf{2 0 1 0}$ \\
\hline Manufactura de alimentos, bebidas y tabaco & 32,0 & 31,6 & 27,5 & 35,3 \\
\hline $\begin{array}{l}\text { Fabricación de productos quimicos, petroliferos, carbón, } \\
\text { caucho y plástico }\end{array}$ & 25,0 & 28,2 & 27,8 & 25,2 \\
\hline Industria textil, prendas de vestir e industrias del cuero & 13,0 & 14,1 & 14,2 & 11,2 \\
\hline Fabricación de productos metálicos, maquinaria y equipos & 9,4 & 6,0 & 7,2 & 5,8 \\
\hline $\begin{array}{l}\text { Fabricación de papel y productos de papel, impresión y } \\
\text { publicación }\end{array}$ & 8,6 & 8,3 & 7,8 & 6,1 \\
\hline $\begin{array}{l}\text { Fabricación de productos minerales nometálicos, excepto } \\
\text { productos de petróleo y carbón }\end{array}$ & 3,8 & 2,6 & 3,2 & 2,5 \\
\hline Industrias básicas de metal & 3,2 & 3,6 & 6,0 & 5,2 \\
\hline Otras industrias manufactureras & 2,7 & 3,7 & 4,0 & 6,5 \\
\hline $\begin{array}{l}\text { Manufactura demadera y productos demadera, incluidos } \\
\text { muebles }\end{array}$ & 2,3 & 1,9 & 2,3 & 2,2 \\
\hline Total Industria & $\mathbf{1 0 0 , 0}$ & $\mathbf{1 0 0 , 0}$ & $\mathbf{1 0 0 , 0}$ & $\mathbf{1 0 0 , 0}$ \\
\hline
\end{tabular}

Fuente: elaboración propia en base a datos del DANE.

\section{La evolución del patentamiento en Colombia}

En contraste con otros países de la región, Colombia no registra actividad en el patentamiento hasta mediados de la década de 1980. Durante 1980-1985 fueron solicitadas solamente tres patentes y durante 1986-1990 un total de 13 durante, todas ellas por no residentes. El número de patentes solicitadas se disparó a partir de 1995, como consecuencia de los cambios en la legislación derivados de la Decisión 344 de 1994 y de la Decisión 486 de 2000, las cuales buscaron cumplir con las exigencias derivadas de la firma de los ADPIC. Sin embargo, aún en años más recientes, las patentes de invención solicitadas a la Oficina de Patentes en Colombia son muy inferiores a las realizadas en Brasil o México. La figura 7 muestra la evolución de las patentes solicitadas por residentes y no residentes en Colombia, donde se destaca la abrumadora presencia de patentes solicitadas por no residentes y la escasa participación de residentes en las actividades de patentamiento.

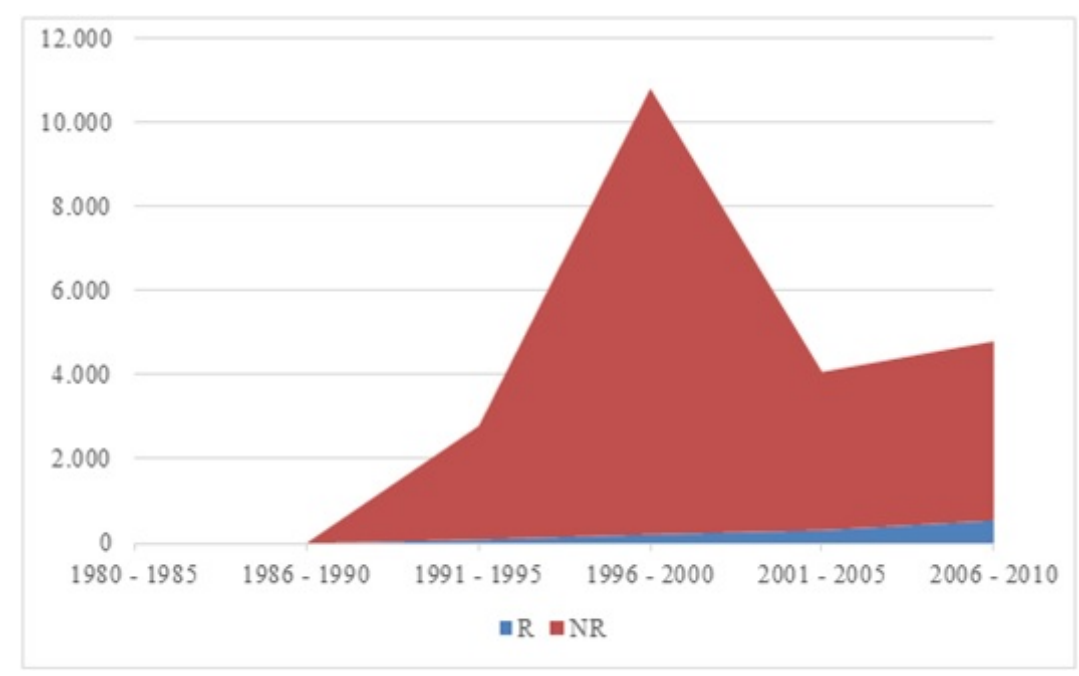

FIGURA 7

Evolución de las patentes solicitadas por residentes (R) y no residentes (NR) en Colombia, 1980-2010 Fuente: elaboración propia en base a datos de PATSTAT. 
La tabla 3 muestra la evolución del número de patentes solicitadas en diferentes campos tecnológicos en los que se clasifican las solicitudes de patentes. Debido a que durante la década de 1980 no se registran solicitudes de patentes en la mayoría de los campos tecnológicos, se muestran los datos a partir de 1990.

TABLA 3

Evolución de las solicitudes de patentes por área tecnológica. Total, residentes (R) y no residentes (NR), 1990-2010

\begin{tabular}{|c|c|c|c|c|c|c|c|c|c|c|c|c|}
\hline \multirow{2}{*}{ Campo tecnológico } & \multicolumn{3}{|c|}{$1990-1995$} & \multicolumn{3}{|c|}{$1996-2000$} & \multicolumn{3}{|c|}{$2001-2005$} & \multicolumn{3}{|c|}{$2006-2010$} \\
\hline & Total & $\mathrm{R}$ & NR & Total & $\mathrm{R}$ & $\mathrm{NR}$ & Total & $\mathrm{R}$ & $\mathrm{NR}$ & Total & $\mathrm{R}$ & NR \\
\hline $\begin{array}{l}\text { Productos farmacéuticos y } \\
\text { cosméticos }\end{array}$ & 345 & 8 & 337 & 2.479 & 3 & 2.476 & 1.097 & 19 & 1.078 & 1.188 & 24 & 1.164 \\
\hline $\begin{array}{l}\text { Productos } \\
\text { orgánica }\end{array}$ & 281 & 0 & 281 & 1.793 & 1 & 1.792 & 845 & 4 & 841 & 1.035 & 11 & 1.024 \\
\hline $\begin{array}{l}\text { Procesamiento quím } \\
\text { básico }\end{array}$ & 387 & 8 & 379 & 979 & 25 & 954 & 274 & 21 & 253 & 446 & 54 & 392 \\
\hline Ingenieria médica & 258 & 4 & 254 & 759 & 8 & & 277 & 14 & 263 & 323 & 33 & 290 \\
\hline Bienes dec & 125 & 8 & 117 & & 14 & & 142 & & 113 & 226 & & 175 \\
\hline & 57 & 8 & 49 & 186 & 29 & 157 & 95 & 27 & 68 & 146 & 37 & 109 \\
\hline & 99 & 3 & 96 & 241 & 19 & 222 & 104 & 25 & 79 & 140 & 36 & 104 \\
\hline Biotecnologia & 52 & 1 & 51 & 256 & 7 & 249 & 106 & 5 & 101 & 139 & 8 & 131 \\
\hline Procedimientos técnic & 99 & 1 & 98 & 334 & 3 & & 93 & 12 & 81 & 129 & 34 & 95 \\
\hline Manejo e impresión & 242 & 3 & 239 & 485 & 14 & 471 & 159 & 19 & 140 & 125 & 19 & 106 \\
\hline Análisis, medición y contr & 62 & 2 & 60 & 263 & 9 & 254 & 111 & 20 & 91 & 104 & 32 & 72 \\
\hline Materiales y metalurgia & 65 & 6 & 59 & 146 & 8 & 138 & 47 & 5 & 42 & 86 & 11 & 75 \\
\hline Componentes eléctricos & 35 & 1 & 34 & 147 & 10 & 137 & 37 & 12 & 25 & 85 & 24 & 61 \\
\hline Procesamiento de materiales & 186 & 7 & 179 & 574 & 5 & 569 & 116 & 11 & 105 & 84 & 17 & 67 \\
\hline Total & 2.789 & 89 & 2.700 & 10.813 & 212 & 10.601 & 4.070 & 306 & 3.764 & 4.802 & 541 & 4.261 \\
\hline
\end{tabular}

Fuente: elaboración propia con base en datos de PATSTAT.

La mayoría de las patentes solicitadas se concentran en sectores que son reconocidos como intensivos en el uso de DPI. Dos campos tecnológicos concentran casi la mitad de las solicitudes de patentes: la farmacéutica y la química orgánica fina. En los años 2006-2010, estos sectores representan el 25\% y el 22\% de las solicitudes, respectivamente. A continuación, los campos que más solicitudes concentran son los de procesamiento químico básico ( $9 \%$, la ingeniería médica ( $7 \%$ y los bienes de consumo y equipos $5 \%$. Los siguientes campos tecnológicos que se presentan en la tabla 3 concentran entre el 3 y el $2 \%$ cada uno.

La cantidad de solicitudes en los diferentes campos tecnológicos no parece estar directamente relacionadas con la fortaleza de la protección de la PI en aquellos sectores con protección específica. Por ejemplo, pese a que la protección de la PI en el sector farmacéutico aumentó menos que en el resto de la región, las solicitudes de patentes en este campo tecnológico aumentaron en 3,44 veces entre 1990-1995 y 2006-2010 mientras que en el sector de productos agrícolas y alimentos donde el incremento de la protección de la PI fue mayor que en el resto de América Latina, las solicitudes de patentes experimentaron un aumento de 1,41 veces entre 1990-1995 y 2006-2010.

Del mismo modo, las solicitudes de patentes tampoco parecen estar relacionadas con los sectores industriales que han demostrado tener un mejor desempeño en las últimas décadas, con excepción tal vez de la industria química y la farmacéutica. El principal sector industrial, el de alimentos, se encuentra en el séptimo lugar en la cantidad de patentes. El número de solicitudes por parte de residentes en los campos tecnológicos que incluyen innovaciones correspondientes a los principales sectores industriales tampoco es relevante.

En el caso de la industria farmacéutica, Colombia ha logrado desarrollar una industria local y un importante mercado de genéricos desde la década de 1960, lo cual fue a la vez el resultado de la confluencia de un sector de la industria local, un grupo industrial estadounidense y una política farmacéutica estatal. De este modo, el Ministerio de Salud logró establecer una política pionera en la región, la cual fortaleció el control de calidad a los medicamentos genéricos y fue favorable a su difusión. El Estado colombiano en su rol de regulador fue capaz de propiciar la armonización entre los intereses de la industria y la sociedad por el acceso a la salud, a través de una estrategia de popularización del consumo de genéricos por parte del Gobierno y de la industria (García, 2017. Esto puede explicar, en parte, los menores índices de protección de la PI en el sector. Sin embargo, este sector es el que registra mayor número de solicitudes de patentes. 
Esta política ha logrado reducir considerablemente los precios de los medicamentos. El apoyo a la industria de genéricos con el An de mantener bajos los precios de los medicamentos se ilustra con un interesante caso en el cual Colombia redujo unilateralmente en un $44 \%$ el precio de un medicamento para combatir el cáncer producido por la farmacéutica Novartis, luego de que el país declarara de interés público su patente en 2016. Esta fue la primera vez en la historia que Colombia declaró una patente de interés público, reduciendo el precio de un medicamento, sin el consentimiento de los titulares de la patente, luego de que fracasara y fuera abandonada una intensa negociación entre el gobierno y la empresa. La decisión permite al laboratorio Novartis, titular de la patente, mantener el monopolio en el mercado, pero con un precio regulado que simula unas condiciones de competencia entre la molécula original y sus genéricas. Inicialmente el medicamento -usado por unos 2.500 pacientes oncológicos en Colombia- no tenía patente, por lo que laboratorios de genéricos ingresaron el fármaco con costos hasta 197\% más bajos, hasta que Novartis logró la concesión por seis años en 2012, lo que implicó la salida de los competidores. ${ }^{9}$

En la figura 8 se observa que la distribución de las solicitudes de patentes es muy sesgada. Unos pocos campos tecnológicos concentran la mayor parte de las solicitudes, mientras que la mayor parte de los campos tecnológicos sólo tienen un número bajo de solicitudes.

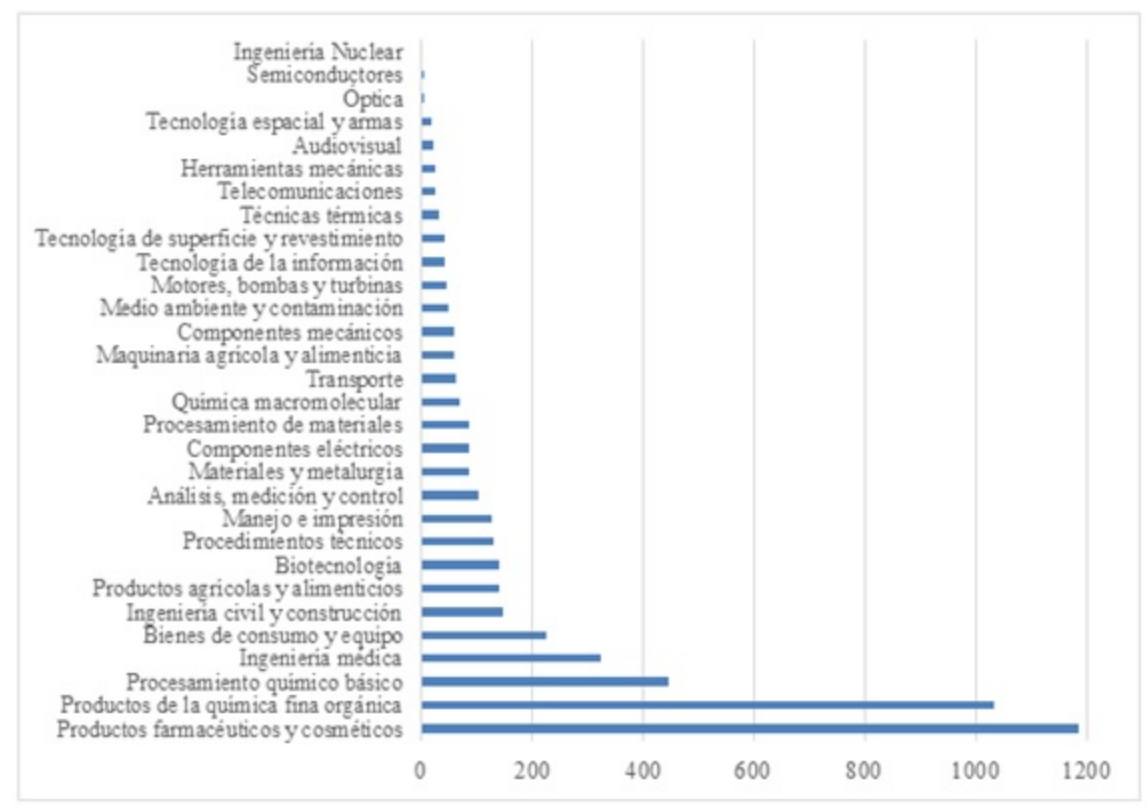

FIGURA 8

Distribución de las solicitudes de patentes por campo tecnológico, 2006-2010

Fuente: elaboración propia con base en datos de PATSTAT.

La concentración de solicitudes por parte de residentes es menos sesgada. Los primeros dominios tecnológicos son: procesamiento químico básico (10\%), bienes de consumo y equipos $(9,4 \%)$, ingeniería civil y construcción $(6,8 \%)$, productos agrícolas y alimentos $(6,7 \%)$, procedimientos técnicos $(6,3 \%)$, ingeniería médica $(6,1 \%)$, y análisis, medición y control (5,9\%). El resto de los dominios tecnológicos acumulan cada uno menos del $5 \%$ y algunos como semiconductores e ingeniería nuclear, tienen sólo una solicitud o no tienen solicitudes presentadas por residentes en todo el período analizado.

En síntesis, durante el período de 1980-2010, Colombia muestra una baja participación local en las actividades de patentamiento. La abrumadora mayoría de solicitudes de patentes de no residentes se concentra además en unos pocos sectores tecnológicos. Este comportamiento puede ser explicado, por un lado, por la relativamente baja tradición de la industria colombiana en el uso de DPI, lo cual puede estar además relacionado con la evolución de la legislación relativa. Pero, principalmente, este comportamiento puede deberse a procesos relacionados con el desarrollo industrial colombiano. Considerando la evolución de la economía colombiana, no es sorprendente que las solicitudes de patentes de los residentes sean bajas 
en relación con las solicitudes de no residentes y en comparación con otros países de América Latina. A continuación, se analiza con más detalle el comportamiento heterogéneo de los residentes y no residentes con respecto a las solicitudes de patentes de invención y modelos de utilidad.

\section{Las empresas multinacionales en las actividades de patentamiento}

En esta sección se analizan las actividades de patentamiento en Colombia de las empresas multinacionales. Como se analizó en la sección previa, existen cuatro campos tecnológicos que concentran el $47 \%$ de las solicitudes de patentes. Los primeros dos sectores son la farmacéutica y la química orgánica fina, ambos se clasifican dentro del campo tecnológico principal de la química. Luego siguen en cantidad de solicitudes de patentes los campos del procesamiento químico básico y de la ingeniería médica. En esta sección se analiza quiénes son los principales solicitantes de patentes en estos campos tecnológicos. Además, se extiende el análisis al sector de la agricultura y alimentos por su relevancia para la economía colombiana y por los cambios que ha sufrido la legislación relativa al sistema de DPI que lo afecta. En general, se observa que la evolución del patentamiento en los diferentes sectores analizados no necesariamente se relaciona con la evolución de los cambios en la legislación, sino que parece seguir una dinámica propia y que puede estar asociada a comportamientos globales de las multinacionales.

\section{Farmacéutica y cosméticos}

Desde 1989, la industria farmacéutica tuvo un proceso de fusiones y adquisiciones que se presentó en tres oleadas (Koenig \& Mezick, 2004). La primera ola de concentración incluye fusiones como la de Bristol-Myers Squibb en 1989 y Smith-Kline Beecham. La segunda ola de fusiones ocurrió en los años 1994 a 1996, cuando American Home Products se fusionó con Ayerst y Wyeth en 1994. Esto fue seguido por Glaxo Wellcome en 1995, Pharmacia y Upjohn, Hoechst A.G. ambas en 1995, y Novartis, anteriormente Ciba-Geigy y Sandoz, en 1996. La tercera ola comenzó en 2000 cuando Pfizer se fusionó con Warner Lambert, y Glaxo se fusionó con Smithkline; mientras que Bayer y Schering se fusionaron en el año 2006.

Los motivos detrás de las fusiones son tema de debate, pero, al igual que en otras industrias, diversos autores señalan principalmente motivos estratégicos. Uno de ellos es el acceso a patentes. Asimismo, algunos análisis plantean que la industria realiza fusiones y adquisiciones buscando ventajas que incluyen economías de escala en investigación y desarrollo (I\&D), acceso a medicamentos en el pipeline, marketing y capacidad de ventas, acceso a mercados, y porque las regulaciones gubernamentales se han vuelto más permisivas (Koenig \& Mezick, 2004; Danzon, Epstein, \& Nicholson, 2007).

La tabla 4 muestra la distribución de las solicitudes de patentes realizadas por no residentes del sector de la farmacéutica y cosmética. Se observa una alta concentración de las solicitudes en las principales empresas multinacionales de la industria farmacéutica mundial, principalmente de Estados Unidos, Inglaterra, Alemania, Suiza y Francia. Consideramos en esta información el proceso de fusiones y adquisiciones, por lo cual las solicitudes de empresas que se fusionaron se muestran de forma conjunta luego de la fusión y separadas anteriormente. Sólo diez de estas empresas concentran en el período 1990-1995 y 1995-2000 más del 60\% de las solicitudes. En 2000-2005 superan el 50\% de las solicitudes, mientras que en 2006-2010 alcanzan el $47 \%$ de las solicitudes. 
TABLA 4

Evolución de las solicitudes de patentes en farmacéutica y cosméticos, 1990-2010

\begin{tabular}{|c|c|c|c|c|c|c|c|c|c|c|}
\hline \multirow{2}{*}{ No rasidentas } & \multirow{2}{*}{ Pals } & \multicolumn{3}{|c|}{$1990-1995$} & \multirow{2}{*}{\multicolumn{2}{|c|}{ No residentes }} & \multirow{2}{*}{ pals } & \multicolumn{3}{|c|}{$1995 \cdot 2000$} \\
\hline & & Patamas & 8 & Acumuliado & & & & Patamas & $\%$ & Acumulado \\
\hline EU ULหr & Estador Unidor & 58 & 17.21 & 17.21 & GLOXO & D SMITHKLINE & Reino Unido & 343 & 13.85 & 13.85 \\
\hline PAIER & Estados Unidos & 38 & 11.28 & 28.49 & PAZER & / / WARNER LAMBERT & Estados Unidos & 325 & 13.17 & 27.02 \\
\hline HOHMQNN LA ROCHE & Sula & 25 & 7.42 & 35.91 & PROCT & TER \& GAMBLE & Estador Unidos & 187 & 755 & 34.57 \\
\hline MEACK & Estador Unidor & 20 & 5.93 & 41.84 & HOFN & MAN LA ROCHE & sula & 134 & 5.41 & 39.98 \\
\hline PROCTER \& GAMBLE & Estados Unidos & 19 & 5.64 & 47.48 & DOEHR & RINGER & Alamania & 108 & 435 & 44.35 \\
\hline SMITH KUNE BEECHAM & Reino Unidso & 19 & 5.64 & 53.12 & Eu uL & & Estados Unidos & 101 & 4.08 & 48.42 \\
\hline BOEHAONGER INGELHEIM PHARMA KG & Alamania & 17 & 5.04 & 38.16 & NOVAS & RTIS / SANDOZZ & Sulaz & 97 & 3.92 & 52.34 \\
\hline BAYER & Alamania & 24 & 4.15 & 62.31 & SCHER & IING & Alamania & 79 & 3.19 & 55.53 \\
\hline SANDOZ AG / NOVARTIS & Sulaz & 9 & 2.67 & 64.99 & BQYER & & Alamania & 75 & 3.03 & 58.56 \\
\hline COLGATE PALMOUNE & Estados Unidor & 6 & 2.78 & 66.77 & АВвOT & TTLAB & Estador Unidor & 38 & 2.34 & 60.90 \\
\hline Rasto de no resildantas & & 107 & 31.75 & 100.00 & Fasto & de no residantes & & 968 & 39.10 & 100.00 \\
\hline \multirow{2}{*}{ No saidentas } & \multirow{2}{*}{ pals } & \multicolumn{3}{|c|}{$2001 \cdot 2005$} & \multirow{2}{*}{\multicolumn{2}{|c|}{ No residentes }} & \multirow{2}{*}{ 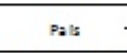 } & \multicolumn{3}{|c|}{$2005 \cdot 2010$} \\
\hline & & Patamas & $\%$ & Acumuli: do & & & & Patantas & $\%$ & Acumulado \\
\hline PFIER / WARNER LAMBERT/PAHARMACLA E UPJOHN & Estados Unidos & 115 & 10.76 & 10.75 & PAZER & R/WYETH & Estados Unidos & 39 & 7.65 & 7.65 \\
\hline AGTRAZENECA & Reino Unido & $s 8$ & 8.15 & 18.92 & ASTRA: & AZENECA AB & Reino Unido & 78 & 6.70 & 14.35 \\
\hline GLAVD SMITHKUNE & Reilno Unido & 82 & 7.61 & 25.53 & BQYVER & SCHERING & Alamania & $\pi 7$ & 6.62 & 20.95 \\
\hline NOVARTIS & Sulze & $\pi$ & 7.14 & 33.57 & NOVAR & & Sula & 67 & 5.76 & 26.72 \\
\hline SANDFI AVENTIS & Fanola & 60 & 5.57 & 39.24 & sanof & FI AVENTIS & Francla & 59 & 5.07 & 31.79 \\
\hline DOEHRINGER INGELHEIM & Estados Unidos & 48 & 4.45 & 43.69 & COLGe & ATE PALMOLNVE & Estados Unidos & 45 & 3.95 & 35.74 \\
\hline WVETH & Estados Unidos & 39 & 3.62 & 47.31 & gOEHR & RINGER INGE LHEIM & Alamania & 38 & 3.25 & 39.00 \\
\hline BAYER & Alamania & 38 & 3.53 & 30.83 & GLaxo & SMITHKLINE & Reino Unido & 37 & 3.18 & 42.18 \\
\hline COLGATE PALMOLIVE & Estador Unidos & 32 & 2.97 & 53.50 & HOFN & MAN LA ROCHE & Sula & 30 & 2.58 & 44.76 \\
\hline HOFFMAN N LA AOCHE & Sulaz & 31 & 2.88 & 56.68 & Lansse & EN PHARMACEUTIC & BSizez & 30 & 2.58 & 4734 \\
\hline Fasto de no resildantes & & 457 & 43.32 & 100.00 & Fastoc & de no residantes & & 613 & 52.65 & 100.00 \\
\hline
\end{tabular}

Fuente: elaboración propia con datos de PATSTAT.

\section{Química fina orgánica y procesamiento químico básico}

La tabla 5 muestra las solicitudes de patentes en el campo tecnológico de la química orgánica fina. Al igual que en el caso de la farmacéutica, las solicitudes de patentes se concentran en unas pocas empresas multinacionales, muchas de las cuales también solicitan patentes en el sector de la farmacéutica y cosmética. En todos los períodos analizados, las solicitudes de patentes de las diez primeras empresas superan el $50 \%$ de las solicitudes totales.

TABLA 5

Evolución de las solicitudes de patentes en química fina orgánica, 1990-2010

\begin{tabular}{|c|c|c|c|c|c|c|c|c|c|}
\hline \multirow{2}{*}{ No residentes } & \multirow{2}{*}{ Pats } & \multicolumn{3}{|c|}{$1990-1995$} & \multirow{2}{*}{ No residentes } & \multirow{2}{*}{ pats } & \multicolumn{3}{|c|}{$1996 \cdot 2000$} \\
\hline & & Patantas & $\%$ & Acumuado & & & Patantas & 86 & Aoumulado \\
\hline Elutur & Estador Unidor & 5 & 18.51 & 18.51 & & Estador Unidor & 201 & 11.22 & 11.22 \\
\hline FIZER & Estados Unidos & $x$ & 13.88 & 32.38 & & Faino Uniso & 141 & 7.87 & 19.08 \\
\hline HOFFMANN LA AOCHE & Sula & $z$ & 8.19 & 40.57 & $\begin{array}{l}\text { SMTHKLINE } \\
\text { HOFNANN LA ROCHE }\end{array}$ & Sutz: & 122 & 6.81 & 25.99 \\
\hline BQYER & Alamenia & D & 3.56 & 44.13 & BAVER & Alemania & 90 & 5.02 & 30.92 \\
\hline DOEHRINGER INGELHEIM & Alsmeni: & 15 & 5.34 & 49.87 & BASF & Alemania & $s 9$ & 4.97 & 35.88 \\
\hline Q.400 & Reiro Unido & 12 & 4.27 & 53.74 & \multirow{2}{*}{$\begin{array}{l}\text { NOVARTIS / SANDOZ / CIBAGEIGY } \\
\text { BOEHR INGER INGELHEIM }\end{array}$} & Surz & 85 & 4.80 & 40.58 \\
\hline RHONE POULENC & Fanela & $\overline{11}$ & 3.91 & 57.5 & & Alamania & 50 & 4.45 & 45.15 \\
\hline MEACK & Estados Unidos & D & 3.56 & 61.21 & $\begin{array}{l}\text { BOERRINGER INGELAEM } \\
\text { EUI ULY }\end{array}$ & Estados Unidos & 79 & 4.41 & 49.55 \\
\hline KMMERLY CLARK & Estados Unidos & 7 & 2.49 & $63 . \pi$ & SCMERING & Alamanla & 55 & 3.07 & 52.52 \\
\hline sQNDDZz & Sula & 6 & 2.14 & 65.84 & \multirow{2}{*}{\multicolumn{2}{|c|}{$\begin{array}{l}\text { GL. AXO } \\
\text { Resto de no raidentes }\end{array}$}} & 52 & 2.90 & 55.52 \\
\hline \multirow[t]{3}{*}{ Pasto de no ra identas } & \multirow{3}{*}{ Pals } & 96 & 34.16 & 10000 & & & 797 & 44.48 & 100.00 \\
\hline & & \multicolumn{3}{|c|}{$2001 \cdot 2005$} & \multirow{2}{*}{ No residentes } & & \multicolumn{3}{|c|}{$2005 \cdot 2010$} \\
\hline & & Patentas & 8 & Acumuado & & Pas & Patantas & 85 & Aoumulado \\
\hline AGTR AIENECA & Reiro Unido & $\pi$ & 9.17 & 9.17 & ASTRAZENECA & Faino Unido & 95 & 9.38 & 9.38 \\
\hline FIIER / PHARMACLA UPJOHN / WAR NER LAMEERT & Alsmanla & 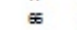 & 7.85 & 17.08 & SAND R AVENTIS & Francia & 75 & 7.40 & 16.78 \\
\hline Q.ANO SMITHKUNE & Reino Unido & 5 & 7.62 & 24.54 & NOVARTIS & suta & 55 & 5.43 & 22.21 \\
\hline SQNDF AVENTIS & Fanda & $\infty$ & 7.14 & 31.78 & BAVER SCHERING & Qulamanla & 35 & 8.39 & 30.60 \\
\hline NOVARTIS / SANDOZ & Sula & 34 & 6.43 & 38.21 & PFIZER / WARNER LAM BERT / WETH & Estador Unidor & 68 & 6.71 & 37.31 \\
\hline BAVER & Alsmanl: & $\Xi 2$ & 6.19 & 44.40 & BRISTOL SQUB B MYERS & Estados Unildos & 29 & 2.85 & 40.18 \\
\hline DOEHRINGER INGELHEIM & Alamaniz & 34 & 4.05 & 48.45 & HOFMANN LAROCHE & suzz & 27 & 2.67 & 42.84 \\
\hline HOFFMANN LA ROCHE & Sula & 31 & 3.69 & 52.24 & BOEMRINGER INGELMEIM & Alemania & 25 & 2.47 & 45.31 \\
\hline WETH & Estrdos Unidos & $\approx$ & 3.45 & 35.90 & GLAVOSMITHKLINE & Raino Unido & 25 & 2.47 & 47.78 \\
\hline BRISTOL SQUIBB MNERS & Estrdos Unidos & $x$ & 2.38 & $37 x$ & ABBOT LAB & Estados Unildor & 25 & 2.47 & 50.25 \\
\hline Pasto de no wa idantas & & 353 & 42.02 & 10000 & Resto de no raidantes & & 504 & 49.75 & 100,00 \\
\hline
\end{tabular}

Fuente: elaboración propia con datos de PATSTAT.

El tercer campo tecnológico que reúne la mayor cantidad de solicitudes de patentes y que también se relaciona con los dos primeros es el del procesamiento químico básico. La tabla 6 muestra la evolución de las solicitudes de patentes en dicho campo tecnológico. Al igual que en los otros campos tecnológicos, las solicitudes se concentran en las principales empresas multinacionales del área. Y muchas de ellas también solicitan patentes en los dos campos tecnológicos analizados anteriormente. Se observa también una alta concentración de solicitudes de patentes en las diez primeras empresas que, dependiendo de los años considerados, superan o alcanzan cerca del $60 \%$ de las solicitudes totales. 
TABLA 6

Evolución de las solicitudes de patentes en procesamiento químico básico, 1990-2010

\begin{tabular}{|c|c|c|c|c|c|c|c|c|c|}
\hline \multirow{2}{*}{ Noresidentes } & \multirow{2}{*}{ Pais } & \multicolumn{3}{|c|}{$1990-1995$} & \multirow{2}{*}{ No residentes } & \multirow{2}{*}{ Pais } & \multicolumn{3}{|c|}{$1996-2000$} \\
\hline & & Patentes & $\%$ & Acumulado & & & Patentes & $\%$ & Acumul sdo \\
\hline PROCTER \& GAMBLE & Estados Unidas & 120 & 31.66 & 31.66 & PROCTER \& GAMBLE & Estadas Unidos & 116 & 12.16 & 12.16 \\
\hline COLGATE PALMOLNE & Estados Unidas & 37 & 9.76 & 41.42 & BASF AG & Alemenis & 106 & 11.11 & 23.27 \\
\hline RHONE POULENC & Francis & 21 & 5.54 & 46.97 & COLGATE PALMOLINE & Estados Unidos & 57 & 5.97 & 29.25 \\
\hline BASF & Alemenis & 16 & 4.22 & 51.19 & BAYER & Alemanis & 55 & 5.77 & 35.01 \\
\hline САВОТ & Estados Unidos & 13 & 3.43 & 54.62 & RHONE POULENC & Francis & 44 & 4.61 & 39.62 \\
\hline KM BERLY CLARK & Estadas Unidas & 13 & 3.43 & 58.05 & NOVARTIS AG / CIBA GEIGY & Suizs & 39 & 4.09 & 43.71 \\
\hline ZENECA & Estadas Unidas & 11 & 2.90 & 60.95 & SCHERING & Alemenis & 32 & 3.35 & 47.06 \\
\hline DOW & Estados Unidas & 9 & 2.37 & 63.32 & UNILEVER & Hols nda/Reino Unido & 27 & 2.83 & 49.90 \\
\hline FMC & Estados Unidas & 7 & 1.85 & 65.17 & DOW & Estadas Unidas & 27 & 2.83 & 52.73 \\
\hline SUMITOMO CHEMICAL & Jspón & 6 & 1.58 & 66.75 & AVENTIS & Francis & 22 & 2.31 & 55.03 \\
\hline Restode no residentes & & 126 & 33.25 & 100.00 & Resto de no residentes & & 429 & 44.97 & 100.00 \\
\hline \multirow{2}{*}{ Noresidentes } & \multirow{2}{*}{ Pais } & \multicolumn{3}{|c|}{$2001 \cdot 2005$} & \multirow{2}{*}{ No residentes } & \multirow{2}{*}{ Pais } & \multicolumn{3}{|c|}{$2006-2010$} \\
\hline & & Patentes & $\%$ & Acumulado & & & Patentes & $\%$ & Acumul sdo \\
\hline BASF & Alemenis & 23 & 9.09 & 9.09 & BAYER & Alemanis & 78 & 19.90 & 19.90 \\
\hline COLGATE PALMOLINE & Estados Unidas & 20 & 7.91 & 17.00 & SYNGENTA & Suiza & 38 & 9.69 & 29.59 \\
\hline BAYER & Alemanis & 41 & 16.21 & 33.20 & BASF & Alemanis & 36 & 9.18 & 38.78 \\
\hline SYNGE NTA /NOVARTIS & Suizs & 25 & 9.88 & 43.08 & DOW AGROSCIENCES & Estados Unidos & 14 & 3.57 & 42.35 \\
\hline ASTRAZENECA & Reino Unido & 8 & 3.16 & 46.25 & COLGATE PALMOLIVE & Estados Unidos & 11 & 2.81 & 45.15 \\
\hline HALLIBURTON ENERGY SERV & Estados Unidas & 8 & 3.16 & 49.41 & DU PONT & Estados Unidos & 11 & 2.81 & 47.96 \\
\hline SUMITOMO & Jspón & 7 & 2.77 & 52.17 & UHDE GMBH & Alemenis & 11 & 2.81 & 50.77 \\
\hline INTEVEP & Venezuels & 7 & 2.77 & 54.94 & ACORDIS KELHEIM GMBH & Alemenis & 9 & 2.30 & 53.06 \\
\hline BP CHEM & Reino Unido & 5 & 1.98 & 56.92 & ROHM \& HAAS & Estadas Unidas & 6 & 1.53 & 54.59 \\
\hline DU PONT & Estados Unidas & 3 & 1.19 & 58.10 & JANSSEN PHARMACE UTICA & Belgics & 6 & 1.53 & 56.12 \\
\hline Restode no residentes & & 106 & 41.90 & 100.00 & Resto de no residentes & & 172 & 43.88 & 100.00 \\
\hline
\end{tabular}

Fuente: elaboración propia con datos de PATSTAT.

\section{Ingeniería médica}

La tabla 7 muestra las solicitudes de patentes en el campo tecnológico de ingeniería médica. En este caso se observa una concentración aún más alta que en los casos anteriores, pues en algunos períodos, las diez primeras empresas multinacionales concentran hasta el $86 \%$ de las solicitudes totales de patentes.

TABLA 7

Evolución de las solicitudes de patentes en ingeniería médica, 1990-2010

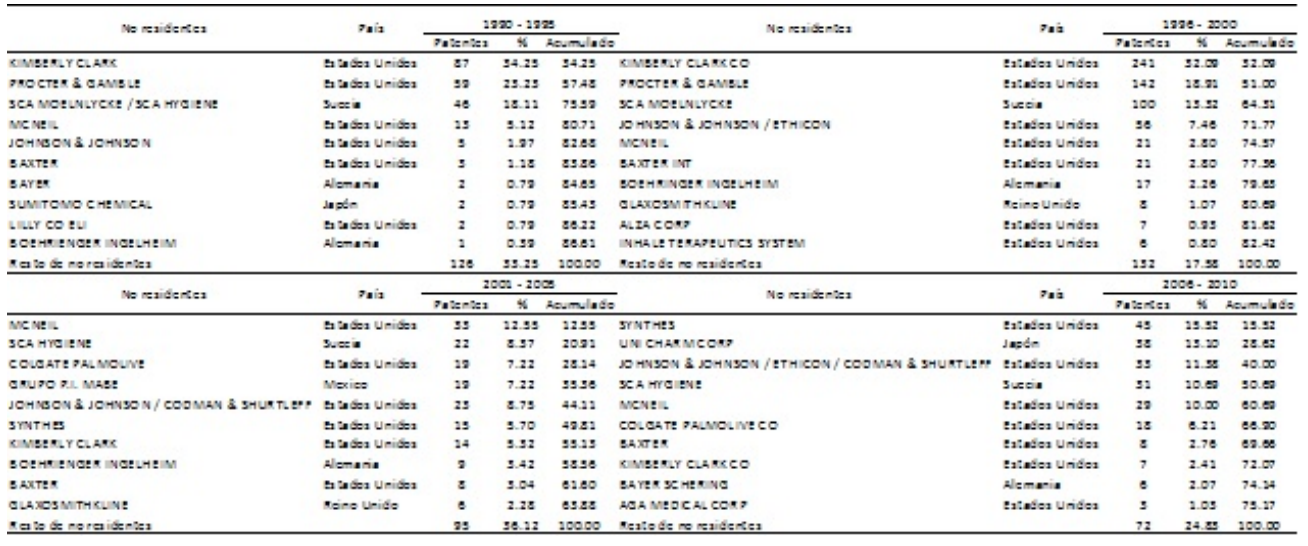

Fuente: elaboración propia con datos de PATSTAT.

\section{Productos agrícolas y alimentos}

La tabla 8 muestra las solicitudes de patentes en el campo tecnológico de productos agrícolas y alimentos. Se observa que existe una mayoría de empresas multinacionales de Estados Unidos que concentraron las solicitudes de patentes en este caso, en particular, entre 1990 y 2005. En 2006-2010 se observa una reducción en la concentración de patentes, lo que contrasta con la alta concentración observada en los períodos anteriores, así como mayor diversidad en el origen de las empresas que solicitan las patentes. 
TABLA 8

Evolución de las solicitudes de patentes en productos agrícolas y alimentos, 1990-2010

\begin{tabular}{|c|c|c|c|c|c|c|c|c|c|}
\hline \multirow{2}{*}{ No residentes } & \multirow{2}{*}{ Pais } & \multicolumn{3}{|c|}{$1990-1995$} & \multirow{2}{*}{ No residentes } & \multirow{2}{*}{ Pais } & \multicolumn{3}{|c|}{$1996-2000$} \\
\hline & & Patentes: & $\%$ & Acumuado & & & Patertes & $\%$ & Acumulado \\
\hline NESTLE & Suiza & 23 & 23.96 & 23.96 & NESTLE SA & Suize & 66 & 29.73 & 29.73 \\
\hline UNILEVER & ReinoUnido & 17 & 17.71 & 41.67 & PROCTER \&. GAMBLLE & Estados Unidos & 19 & 8.56 & 38.29 \\
\hline KRAFT FOODS & Estados Unidos & 6 & 6.25 & 47.92 & WAR NER LAMBERT & Estados Unidos & 9 & 4.05 & 42.34 \\
\hline CORN PRODUCTS & Esta dos Unidos & 4 & 4.17 & 52.08 & KRAFT FOODS / GEN FOODS & Estados Unidos & 16 & 7.21 & 49.55 \\
\hline PRO CTER \&. GAMBLE & Esta dos Uni dos & 4 & 4.17 & 56.25 & GEN MLLS & Estados Unidos & 8 & 3.60 & 53.15 \\
\hline COCA COLA & Esta dos Unidos & 3 & 3.13 & 59.38 & PILLSBURY & Estados Unidos & 8 & 3.60 & 56.76 \\
\hline ELI LILLY & Esta dos Unidos & 3 & 3.13 & 62.50 & RHONE POULENC & Francia & 7 & 3.15 & 59.91 \\
\hline NAB ISCO INC & Esta dos Uni dos & 3 & 3.13 & 65.63 & ABBOTT LAB & Estados Unidos & 6 & 2.70 & 62.61 \\
\hline WARNER LAMBERT & Esta dos Unidos & 3 & 3.13 & 68.75 & RECOT & Estados Unidos & 5 & 2.25 & 64.86 \\
\hline WR GRACE & Esta dos Unidos & 2 & 2.08 & 70.83 & \multirow{2}{*}{$\begin{array}{l}\text { UNILEVER } \\
\text { Resto de no residentes }\end{array}$} & ReinoUnido & 5 & 2.25 & 67.12 \\
\hline Resto de no residentes & & 28 & 29.17 & 100.00 & & & 73 & 32.88 & 100.00 \\
\hline \multirow{2}{*}{ No residentes } & \multirow{2}{*}{ Pais } & \multicolumn{3}{|c|}{$2001-2005$} & \multirow{2}{*}{ No residentes } & \multirow{2}{*}{ Pais } & \multicolumn{3}{|c|}{$2005-2010$} \\
\hline & & Patentes & $\%$ & Acumulado & & & Patertes & $\%$ & Acumulado \\
\hline NESTLE / NEST EC & Suiza & 18 & 22.78 & 22.78 & NESTLE / NESTEC & Suiza & 14 & 13.46 & 13.45 \\
\hline KRAFT FOODS & Esta dos Unidos & 15 & 18.99 & 41.77 & ABBOTT LAB & Estados Unidos & 4 & 3.85 & 17.31 \\
\hline WM WRIGLEY & Esta dos Uni dos & 4 & 5.06 & 46.84 & QUAKER OATS & Estados Unidos & 4 & 3.85 & 21.15 \\
\hline FRITO LAY / RECOT & Esta dos Unidos & 4 & 5.06 & 51.90 & RAISIO NUTRITION LTD & Finlandia & 3 & 2.88 & 24.04 \\
\hline CADBURY & Esta dos Unidos & 3 & 3.80 & 55.70 & UNILEVER & Reino Unido & 3 & 2.88 & 26.92 \\
\hline UNILEVER & Esta dos Uni dos & 3 & 3.80 & 59.49 & BAYER & Alemania & 3 & 2.88 & 29.81 \\
\hline MCNEIL & Esta dos Unidos & 2 & 2.53 & 62.08 & ADSSEO FRANCE SAS & Francia & 2 & 1.92 & 31.73 \\
\hline QUAKER OATS & Esta dos Unidos & 2 & 2.53 & 64.56 & CARGLLINC & Esta dos Unidos & 2 & 1.92 & 33.65 \\
\hline ABBOTT LAB & Esta dos Uni dos & 1 & 1.27 & 65.82 & FRITO LAY & Estados Unidos & 2 & 1.92 & 35.58 \\
\hline BOEHRINGER INGELHEIM & Alemania & 1 & 1.27 & 67.09 & HEINEKEN SUPPLY CHAIN & Holand & 2 & 1.92 & 37.50 \\
\hline Resto de no residentes & & 26 & 32.91 & 100.00 & Resto de no residentes & & 65 & 62.50 & $100 . \infty$ \\
\hline
\end{tabular}

Fuente: elaboración propia con datos de PATSTAT.

De acuerdo con los datos, la evolución de solicitudes de patentes en el sector de productos agrícolas y alimentos no muestra un comportamiento muy diferente al observado en los otros campos tecnológicos a pesar de que los sistemas de DPI específicos para la agricultura tendieron a fortalecerse más en términos relativos.

\section{Las actividades de patentamiento, formas de innovar y el uso de mecanismos alternativos de protección de PI en Colombia}

Los datos sobre patentamiento muestran un enorme rezago de las solicitudes de residentes colombianos frente a las de no residentes. Esta situación no cambió a lo largo del período de análisis ni en años posteriores, sino que por el contrario se agudizó debido al significativo aumento de las solicitudes de patentes de no residentes.

El patentamiento de los colombianos en el exterior también es bajo en relación con otros países en desarrollo, incluso en comparación con países de la región. Por ejemplo, Brasil, México y Argentina, prácticamente, quintuplican la cantidad de solicitudes de patentes durante el mismo período. Con respecto a otros países que registraron mejores desempeños económicos pero que tenían un nivel de desarrollo similar al de Colombia en la década de 1950 (como Taiwán, Singapur o Corea), las actividades de patentabilidad internacional de Colombia son precarias. Los sectores donde se encuentran, mayoritariamente, las patentes colombianas son salud, durante todo el período analizado, y tecnologías de la información y comunicaciones, desde la década del 2000 (Sánchez, Medina, \& León, 2007).

Existen varios factores que pueden explicar este comportamiento. En primer lugar, en este período la economía colombiana tuvo la desindustrialización y además la apertura a la inversión extranjera. Ambos fenómenos pueden haber impulsado el patentamiento de no residentes y reducido el de residentes. Pero también, en segundo lugar, Colombia ha tenido desde antes del proceso de desindustrialización una baja propensión a utilizar DPI para proteger sus innovaciones. Malaver Rodríguez y Vargas Pérez (2004) muestran que aun las empresas colombianas que obtienen innovaciones patentables, es decir, nuevas para el mercado internacional, no patentan. En este sentido, el bajo uso de formas de DPI por parte de los colombianos puede estar asociado no necesariamente a una baja actividad inventiva, sino a otros fenómenos que llevan a un bajo patentamiento, como el uso de mecanismos alternativos de PI. 
Aunque no se dispone de datos conAables sobre el uso de mecanismos alternativos de PI para todo el período de nuestro análisis, los datos disponibles de la Encuesta de Desarrollo e Innovación Tecnológica EDIT - para la industria manufacturera durante el período de 2007 a 2010 permiten observar el uso de mecanismos informales de protección de PI (Agura 9). En los años 2007-2008, 1.184 empresas declararon el uso de algún mecanismo alternativo de PI, y para los años 2009-2010 ese número subió a 2.857. Entre los mecanismos más usados están los acuerdos de confidencialidad con los empleados $(42,65 \%)$ y con otras empresas (28,89\%), y el secreto industrial (19,76\%).

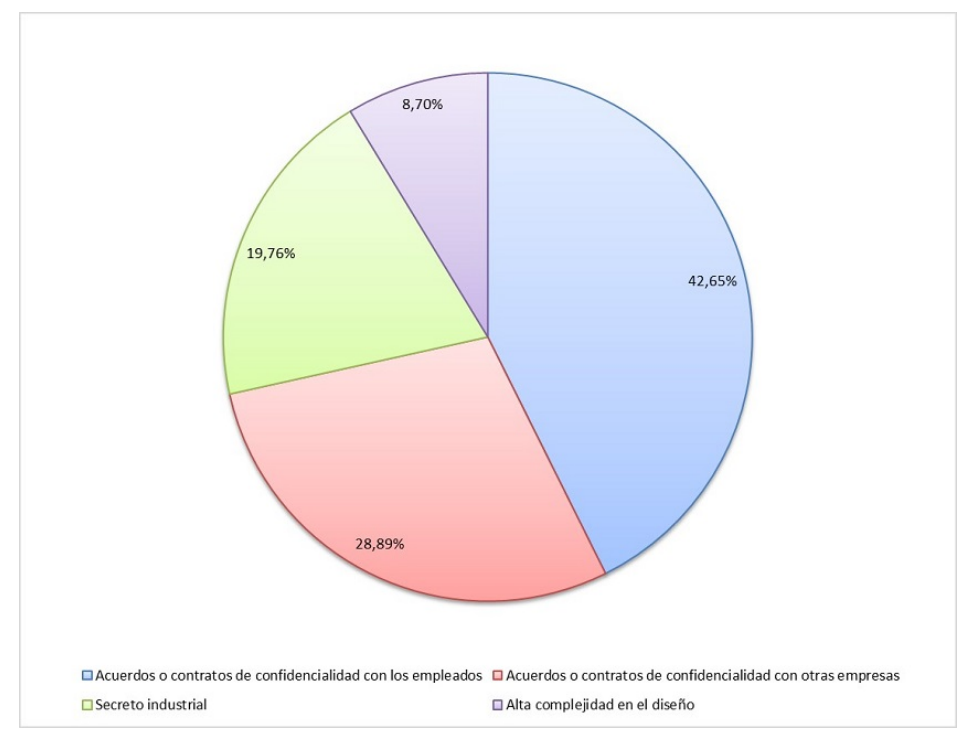

FIGURA 9

Mecanismos alternativos de protección de la propiedad intelectual, 2007-2008

Fuente: elaboración propia con datos de la Encuesta EDIT IV-V 2007-2008, DANE.

En segundo lugar, diversos autores muestran que las empresas colombianas incorporan el cambio tecnológico, principalmente, a través de las importaciones de bienes de capital, en lugar de obedecer al esfuerzo endógeno y que la mayor parte de la inversión de las empresas corresponde a innovaciones incrementales basadas en conocimientos ya existentes (Malaver Rodríguez \& Vargas Pérez, 2004; Langebaek $\&$ Vásquez, 2007). Debido a que las tecnologías importadas se desarrollan en sus contextos y para responder a las necesidades de sus sistemas empresariales, en general, no se ajustan a las particularidades de las empresas colombianas, por lo que éstas deben realizar adaptaciones para su utilización productiva. Por ello, los procesos de innovación en Colombia, como también en otros países en desarrollo, tienen un carácter adaptativo e incremental que los distingue (Jaramillo, Lugones, \& Salazar, 2000). Esto mismo explica que exista una elevada cantidad de empresas colombianas que reportan innovaciones en tecnologías de gestión y de proceso, así como muchas otras que invierten en diseño industrial con el fin de lograr innovaciones de producto a partir de la adaptación.

Estas características de las actividades de innovación en Colombia configuran un tipo particular de formas de innovar (Malaver \& Vargas, 2013) que ayuda a comprender por qué razón son bajas las solitudes de patentes en la industria colombiana. Como Malaver y Vargas (2013) señalan, en industrias de alta tecnología y rápido crecimiento, la $\mathrm{I}+\mathrm{D}$ es fundamental para la generación de innovaciones e invenciones. Sin embargo, en industrias de baja y media tecnología como la colombiana, son más importantes las capacidades para identificar, asimilar y aplicar las tecnologías de países líderes a los mercados y empresas locales, lo que genera que las actividades de innovación se basen más en adaptaciones que generan desarrollos innovadores apoyados en la ingeniería, el diseño o el marketing. Esto a su vez explicaría la alta proporción en el uso de las empresas colombianas de mecanismos formales - modelos de utilidad-e informales -secreto industrial, registro de marca y derechos de autor- de PI diferentes a las patentes de invención.

Una última explicación del bajo patentamiento de residentes se puede plantear a partir de los cambios en las legislaciones relacionadas con la PI, cuyos efectos sin embargo pueden ser más difíciles de vislumbrar. En 1994 un cambio en la legislación sobre patentes reglamentó además lo que denominó la "pequeña invención" 
plausible de ser protegida por el "modelo de utilidad". Este último otorgó protección como una patente, pero sin evaluar el nivel o altura inventiva de la creación, por lo cual debe sólo cumplir los requisitos de novedad y aplicación industrial (Mayor, 2005). Este cambio puede ayudar a entender la dinámica del patentamiento colombiano, porque generó una mayor participación de los residentes en las solicitudes de modelos de utilidad y no en las solicitudes de patentes de invención, lo cual puede estar vinculado a su vez con predominancia de las innovaciones basadas en la imitación desarrolladas en el país.

Los datos de la tabla 9 soportan esta idea e ilustran la distribución de residentes y no residentes en las solicitudes de patentes de invención y modelos de utilidad para proteger sus invenciones. Se observa que mientras las solicitudes de patentes se concentran en los no residentes, lo contrario ocurre con las solicitudes de modelos de utilidad, dependiendo del año, las solicitudes realizadas por residentes alcanzan hasta el 94\% del total de solicitudes de modelos de utilidad. Esto permite sostener que los modelos de utilidad pueden ser considerados una forma de protección de la PI más acorde con las actividades de invención y formas de innovar de los países en desarrollo, las cuales se basan en buena medida en la copia, adaptación a la realidad local y la mejora de invenciones disponibles a nivel mundial. Pese a constituir innovaciones, en muchos casos, este tipo de invenciones no pueden ser protegidas por patentes. Por lo tanto, las solicitudes de patentes pueden no reflejar fielmente las actividades de invención en Colombia ya que la mayor parte de las solicitudes realizadas por residentes son de modelos de utilidad y no de patentes de invención.

TABLA 9

Evolución de los modelos de utilidad y de las patentes de invención solicitadas por residentes y no residentes, 1991-2016

\begin{tabular}{|rrrrrrrrrrr|}
\hline \multirow{2}{*}{ Año } & \multicolumn{4}{c}{ Patentes Solicitadas } & \multicolumn{4}{c|}{ Modelos de Utilidad Solicitados } \\
\cline { 2 - 7 } & R & Total & \% R & \% NR & \multicolumn{1}{c|}{ R } & NR & Total & $\%$ R & $\%$ NR \\
\hline 1991 & 30 & 530 & 560 & 5,36 & 94,64 & 5 & 2 & 7 & 71,43 & 28,57 \\
1992 & 42 & 548 & 590 & 7,12 & 92,88 & 40 & 6 & 46 & 86,96 & 13,04 \\
1993 & 42 & 755 & 797 & 5,27 & 94,73 & 65 & 9 & 74 & 87,84 & 12,16 \\
1994 & 33 & 802 & 835 & 3,95 & 96,05 & 61 & 18 & 79 & 77,22 & 22,78 \\
1995 & 47 & 1.018 & 1.065 & 4,41 & 95,59 & 65 & 14 & 79 & 82,28 & 17,72 \\
1996 & 32 & 1.055 & 1.087 & 2,94 & 97,06 & 67 & 15 & 82 & 81,71 & 18,29 \\
1997 & 60 & 1.371 & 1.431 & 4,19 & 95,81 & 66 & 18 & 84 & 78,57 & 21,43 \\
1998 & 49 & 1.524 & 1.573 & 3,12 & 96,88 & 66 & 15 & 81 & 81,48 & 18,52 \\
1999 & 40 & 1.462 & 1.502 & 2,66 & 97,34 & 78 & 13 & 91 & 85,71 & 14,29 \\
2000 & 84 & 1750 & 1.834 & 4,58 & 95,42 & 116 & 15 & 131 & 88,55 & 11,45 \\
2001 & 73 & 419 & 492 & 14,84 & 85,16 & 160 & 18 & 178 & 89,89 & 10,11 \\
2002 & 88 & 497 & 585 & 15,04 & 84,96 & 168 & 21 & 189 & 88,89 & 11,11 \\
2003 & 82 & 1.172 & 1.254 & 6,54 & 93,46 & 165 & 21 & 186 & 88,71 & 11,29 \\
2004 & 83 & 1.407 & 1.490 & 5,57 & 94,43 & 147 & 25 & 172 & 85,47 & 14,53 \\
2005 & 157 & 1.655 & 1.812 & 8,66 & 91,34 & 161 & 12 & 173 & 93,06 & 6,94 \\
2006 & 168 & 1.919 & 2.087 & 8,05 & 91,95 & 228 & 15 & 243 & 93,83 & 6,17 \\
2007 & 138 & 1.911 & 2.049 & 6,73 & 93,27 & 159 & 19 & 178 & 89,33 & 10,67 \\
2008 & 125 & 1.906 & 2.031 & 6,15 & 93,85 & 186 & 15 & 201 & 92,54 & 7,46 \\
2009 & 126 & 1.662 & 1.788 & 7,05 & 92,95 & 201 & 11 & 212 & 94,81 & 5,19 \\
2010 & 129 & 1.867 & 1.996 & 6,46 & 93,54 & 169 & 19 & 188 & 89,89 & 10,11 \\
2011 & 201 & 1.890 & 2.091 & 9,61 & 90,39 & 219 & 26 & 245 & 89,39 & 10,61 \\
2012 & 209 & 2.017 & 2.226 & 9,39 & 90,61 & 257 & 25 & 282 & 91,13 & 8,87 \\
2013 & 242 & 1.939 & 2.181 & 11,10 & 88,90 & 239 & 36 & 275 & 86,91 & 13,09 \\
2014 & 269 & 1.954 & 2.223 & 12,10 & 87,90 & 182 & 21 & 203 & 89,66 & 10,34 \\
2015 & 322 & 1.932 & 2.254 & 14,29 & 85,71 & 193 & 24 & 217 & 88,94 & 11,06 \\
2016 & 545 & 1.658 & 2.203 & 24,74 & 75,26 & 248 & 22 & 270 & 91,85 & 8,15 \\
\hline & & & & & & & & & &
\end{tabular}

Fuente: elaboración propia con datos del SIC (www.sic.gov.co/estadisticas-propiedad-industrial).

Finalmente, otro cambio en la legislación consideró un fenómeno que se observaba ya desde 1960 en Colombia: el surgimiento de conocimientos y creaciones susceptibles de ser patentados en centros de investigación, laboratorios y universidades nacionales (Mayor, 2005). La nueva legislación consideró la posibilidad de difundir y utilizar dichos conocimientos y creaciones, con fines académicos y científicos, sin que las mismas perdieran la cualidad de novedad, necesaria para el patentamiento. Esto se ajustó mediante la figura de "reporte de concepción". El patentamiento por parte de universidades colombianas creció entre 1988 y 2010, acumulando un total de 69 solicitudes de patentes en el período. Las solicitudes de patentes de invención se distribuyeron en las siguientes disciplinas: ingeniería química (33,7\%), ingeniería mecánica $(24,8 \%)$, biotecnología $(21,6 \%)$, química pura $(8,7 \%)$, ingeniería eléctrica $(7,7 \%)$ y química farmacéutica 
(3,6\%) (González-Gélvez \& Jaime, 2013). Estas reformas, y las discutidas con anterioridad, llevaron a que durante la década de 1990 las universidades, institutos públicos de investigación y la Superintendencia de Industria y Comercio generaran material didáctico, libros, manuales de divulgación y tesis de grado, que tenían el fin de difundir información y de instruir al inventor colombiano sobre los pasos necesarios para el patentamiento.

El conjunto de estos factores: reformas de la legislación, difusión de información e incentivos al uso de DPI, tuvieron efectos, aunque probablemente de poca magnitud, en las actividades de patentamiento de los residentes colombianos.

\section{Conclusiones}

Este estudio analizó el proceso de fortalecimiento de los derechos de propiedad intelectual y su relación con el patentamiento en Colombia. La evidencia construida muestra que los sistemas de protección de la propiedad intelectual en Colombia se vieron fortalecidos a lo largo de los años analizados por tres fenómenos: la participación de Colombia en procesos de integración regional, el ingreso a la OMC y la consecuente adhesión a los ADPIC, y la firma de acuerdos comerciales con capítulos que exigen reformas de los sistemas de DPI. Nuestro análisis de las patentes muestra que este fortalecimiento no ha incentivado la innovación local medida en términos de solicitudes de patentes, sino que sólo ha impulsado las solicitudes de patentes de no residentes. Esto implica que el efecto real de los sistemas de DPI ha sido crear una barrera a la entrada de empresas nacionales y han tendido a generar monopolios, lo cual puede constituir un obstáculo a la innovación y al desarrollo económico del país. Asimismo, el patentamiento no está directamente relacionado con los cambios en la legislación ni con los sectores más productivos o innovadores, sino que sigue una dinámica guiada por comportamientos globales de empresas multinacionales en algunos sectores intensivos en el uso de DPI. Este comportamiento se ha evidenciado también en otros países en desarrollo como la India (Mani, 2020). La conclusión general de lo anterior es que el aumento significativo de los niveles de protección fue poco efectivo para estimular el patentamiento de residentes y, en cambio, generó un contexto institucional favorable al aumento de patentes de multinacionales que buscaban capturar mayores rentas en sus industrias. En este sentido, se sostiene que los niveles de protección de los DPI han sido poco efectivos en estimular la innovación.

Las razones a las que podría atribuirse ese impacto tan débil sobre el patentamiento local y tan fuerte sobre el patentamiento de multinacionales se relacionan con el hecho que el fortalecimiento de los DPI ocurrió en un contexto de desindustrialización que afectó las empresas industriales, adicional a un aumento de flujos de inversión extranjera que llevó a que las empresas multinacionales llegaran al país a buscar una mayor protección de sus invenciones. Esto hizo que las reformas en los sistemas de PI tuvieran un efecto diferencial en las solicitudes de patentes de residentes y no residentes. Además, el débil estímulo del fortalecimiento de los DPI a las patentes de residentes tiene que ver con que las actividades de innovación de las empresas colombianas se caracterizan por ser incrementales y se basan en procesos de adaptación de tecnología extranjera, por lo tanto, buena parte de las innovaciones no son aptas para realizar una solicitud de patente, lo que hizo que los efectos positivos esperados del fortalecimiento de la PI sobre la innovación no afectaran a las empresas nacionales. En este sentido, las solicitudes de patentes de residentes no reflejan las características de las actividades de innovación ni los métodos de protección de la propiedad intelectual más adecuados para incentivar la innovación en Colombia. Por dicha razón es importante revisar y reformular la política pública de propiedad intelectual de manera que se desarrollen incentivos y diseñen mecanismos de protección de la PI más adecuados para las actividades de innovación colombianas que se basan en la imitación, adaptación a la realidad local y mejora de invenciones disponibles a nivel mundial. 
Finalmente, este estudio tiene varias limitaciones que pueden estimular líneas de investigación futura sobre la propiedad intelectual y la innovación en Colombia. Por ejemplo, es importante profundizar en los mecanismos causales de la relación entre fortalecimiento de los DPI, las patentes y la innovación y desempeño de las empresas. Estudios que exploten datos panel - por ejemplo, de las EDITs- sobre el efecto de las patentes sobre la innovación y sobre las estrategias de apropiación de rentas vía el uso de mecanismos formales e informales de propiedad intelectual ayudarían a entender mejor cuáles son los incentivos relacionados con la PI más adecuados para estimular la innovación en Colombia.

\section{Referencias}

Bessen, J., \& Maskin, E. (2009). Sequential innovation, patents, and imitation. The RAND Journal of Economics, 4O(4), 611-635. https://doi.org/10.2139/ssrn.206189

Biadgleng, E. T. \& Maur, J.C. (2011). The Influence of Preferential Trade Agreements on the implementation of intellectual property rights in developing countries: A first look. UNCTAD-ICTSD Project on IPRs and Sustainable Development Paper No. 33. SSRN: https://ssrn.com/abstract=1962832.

Boldrin, M., \& Levine, D. K. (2008). Against intellectual monopoly. Cambridge: Cambridge University Press. https:/ /doi.org/10.1017/CBO9780511510854

Brando, C. (2019). La industria en el siglo XX. En S. Kalmanovitz (ed.), Breve historia económica de Colombia. Bogotá: Taurus.

Campi, M., \& Dueñas, M. (2019). Intellectual property rights, trade agreements, and international trade. Research Policy, 48(3), 531-545. https://doi.org/10.1016/j.respol.2018.09.011

Campi, M., \& Nuvolari, A. (2015). Intellectual property protection in plant varieties: A worldwide index, 1961 - 2011. Research Policy, 44(4), 951-964. https://doi.org/10.1016/j.respol.2014.11.003

Campi, M., \& Nuvolari, A. (2020). Intellectual property rights and agricultural development: Evidence from a worldwide index of IPRs in agriculture, 1961-2018. Journal of Development Studies, Ahead-of-print, 1-19. http s://doi.org/10.1080/00220388.2020.1817395.

Campi, M., Dueñas, M., \& Lachman, J. (2017). Acuerdos comerciales y derechos de propiedad intelectual. Evidenciaspara reflexionar sobre el caso argentino. Ministerio de Producción, República Argentina. https://mercedescampi.files .wordpress.com/2018/08/word_ministerio_final.pdf.

Chaudhuri, S., Goldberg, P. K., \& Jia, P. (2006). Estimating the effects of global patent protection in Pharmaceuticals: A case study of Quinolones in India. American Economic Review, 96(5), 1477-1514. https://doi.org/10.1257/ aer.96.5.1477

Cohen, W. M., Nelson, R. R., \& Walsh, J. P. (2000). Protecting their intellectual assets: Appropriability conditions and why US manufacturing firms patent (or not), No. w7552. National Bureau of Economic Research. https://doi. org/10.3386/w7552

Danzon, P. M., Epstein, A., \& Nicholson, S. (2007). Mergers and acquisitions in the pharmaceutical and biotech industries. Managerial and Decision Economics, 28(4-5), 307-328. https://doi.org/0.2139/ssrn.468301

Deardorff, A. V. (1992). Welfare Effects of Global Patent Protection. Economica, 59, 35-51. https://doi.org/10.230 $7 / 2555064$

Dür, A., Baccini, L., \& Elsig, M. (2014). The design of international trade agreements: Introducing a new dataset. The Review of International Organizations, 9(3), 353-375. https://doi.org/10.1007/s11558-013-9179-8

Echavarría, J. J. \& Villamizar, M. (2007). El proceso Colombiano de desindustrialización. En J. Robinson \& M. Urrutia (eds.), Economia Colombiana del siglo XX: Un análisis cuantitativo. Bogotá: Fondo de Cultura Económica.

Eslava, M., Haltiwanger, J., Kugler, A., \& Kugler, M. (2004). The effects of structural reforms on productivity and profitability enhancing reallocation: evidence from Colombia. Journal of Development Economics, 75(2), 333-371. https://doi.org/10.1016/j.jdeveco.2004.06.002 
Forero-Pineda, C., Laureiro-Martínez, D. \& Marín, A. (2011). Innovation patterns and intellectual property in SMEs of a developing country. Innovar, 21(42), 113-127. http://www.scielo.org.co/scielo.php?script=sci_arttext\&pi $\mathrm{d}=\mathrm{S} 0121-50512011000400010$

Frankel, S. (2011). Legitimidad y finalidad de los capítulos de propiedad intelectual en los tratados de libre comercio (TLC). Revista Propiedad Inmaterial, 15, 169-187. https://revistas.uexternado.edu.co/index.php/propin/artic le/view/3004

García, V. M. (2017). Los medicamentos genéricos en Colombia: industria, políticas de salud y farmaceutización durante la década de 1960. Historia Crítica, 65, 115-137. https://doi.org/10.7440/histcrit65.2017.06

Ginarte, J. C., \& Park, W. G. (1997). Determinants of patent rights: A cross-national study. Research Policy, 26(3), 283-301. https://doi.org/10.1016/S0048-7333(97)00022-X

González-Gélvez, D. M., \& Jaime, A. (2013). El patentamiento universitario en Colombia. Journal of Technology, Management \& Innovation, 8, 233-245. https://doi.org/10.4067/S0718-27242013000300050

Hall, B. H., Helmers, C., Rogers, M., \& Sena, V. (2013). The importance (or not) of patents to UK firms. Oxford Economic Papers-New Series, 65(3), 603-629. https://doi.org/10.1093/oep/gpt012

Helpman, E. (1993). Innovation, imitation, and intellectual property rights. Econometrica, 61(6), 1247-1280. https: //doi.org/10.2307/2951642

Henry, C., \& Stiglitz, J. E. (2010). Intellectual property, dissemination of innovation and sustainable development. Global Policy, 1(3), 237-251. https://doi.org/10.1111/j.1758-5899.2010.00048.x

Hofmann, C., Osnago, A., \& Ruta, M. (2017). Horizontal depth: A new database on the content of preferential trade agreements. World Bank Policy Research Working Paper 7981. Washington DC: World Bank.

Jaramillo, H., Lugones, G., \& Salazar, M. (2000). Manual para la normalización de indicadores de innovación tecnológica en América Latina y el Caribe, Manual de Bogotá. Bogotá, OEA/RICyT, Tres Culturas.

Kalmanovitz, S. (2011). Nueva historia económica de Colombia. Bogotá: Taurus.

Kashcheeva, M. (2013). The role of foreign direct investment in the relation between intellectual property rights and growth. Oxford Economic Papers, 65(3), 699-720. https://doi.org/10.1093/oep/gpt015

Koenig, M. E., \& Mezick, E. M. (2004). Impact of mergers \& acquisitions on research productivity within the pharmaceutical industry. Scientometrics, 59(1), 157-169. https://doi.org/10.1023/B:SCIE.0000013304.40957 $.0 \mathrm{~d}$

Kohl, T., Brakman, S., \& Garretsen, H. (2016). Do trade agreements stimulate international trade differently? Evidence from 296 trade agreements. The World Economy, 39(1), 97-131. https://doi.org/10.1111/twec.12272

Langebaek, A., \& Vásquez, D. (2007). Determinantes de la actividad innovadora en la industria manufacturera colombiana. Borradores de Economia, 433. Bogotá: Banco de la República.

Liu, M., \& La Croix, S. (2015). A cross-country index of intellectual property rights in pharmaceutical inventions. Research Policy, 44(1), 206-216. https://doi.org/10.1016/j.respol.2014.07.004

Malaver Rodríguez, F., \& Vargas Pérez, M. (2004). El comportamiento innovador en la industria colombiana: una exploración de sus recientes cambios. Cuadernos de Administración, 17(27), 33-61. https://revistas.javeriana.ed u.co/index.php/cuadernos_admon/article/view/5428

Malaver Rodríguez, F., \& Vargas Pérez, M. (2013). Formas de innovar y sus implicaciones de política: lecciones de una experiencia. Cuadernos de Economia, 32(60), 499-532. https://revistas.unal.edu.co/index.php/ceconomia/arti cle/view/40123

Mani, S. (2020). India’s patenting record since TRIPS compliance of her patent regime. Asian Journal of Technology Innovation, 1-28. https://doi.org/10.1080/19761597.2020.1829977

Mansfield, E. (1986). Patents and innovation: An empirical study. Management Science, 32(2), 173-181. https://doi .org/10.1287/mnsc.32.2.173

Mayor, A. (2005). Inventos y patentes en Colombia, 1930-2000: de los limites de las herramientas a las fronteras del conocimiento. Medellín: ITM. 
McCalman, P. (2001). Reaping what you sow: An empirical analysis of international patent harmonization. Journal of International Economics, 55(1), 161-186. https://doi.org/10.1016/S0022-1996(01)00091-5

Mercurio, B. (2006). TRIPS-plus Provisions in FTAs: Recent Trends, en F. Lorand Bartels (ed.), Regional Trade Agreements and the WTO Legal System. Oxford: Oxford University Press.

Moreno, J.C.C. (2015). Cambio técnico en sector industrial en Colombia: hechos estilizados de veinte años de apertura económica. Revista Científica Horizonte Empresarial, 2(1), 1-29. http://revistas.uss.edu.pe/index.php/EMP/ar ticle/view/127

Ortiz, C. H., Uribe, J. I., \& Vivas, H. (2009). Transformación industrial, autonomía tecnológica y crecimiento económico: Colombia 1925-2005. Archivos de Economía, 352, 1-57. https://ideas.repec.org/p/col/000118/00 5283.html

Papageorgiadis, N., \& Sharma, A. (2016). Intellectual property rights and innovation: A panel analysis. Economics Letters, 141, 70-72. https://doi.org/10.1016/j.econlet.2016.01.003

Park, W. G. (2008). International patent protection: 1960-2005. Research Policy, 37(4), 761-766. https://doi.org/10 $.1016 /$ j.respol.2008.01.006

Robinson, J., \& Urrutia, M. (eds.) (2007). Economía Colombiana del siglo XX: Un análisis cuantitativo. Bogotá: Fondo de Cultura Económica.

Sánchez, J. M., Medina, J. E., \& León, A. M. (2007). Publicación internacional de patentes por organizaciones inventores de origen colombiano. Cuadernos de Economia, 26(47), 247-270. https://revistas.unal.edu.co/index .php/ceconomia/article/view/1085

Sweet, C., \& Eterovic, D. (2019). Do patent rights matter? 40 years of innovation, complexity and productivity. World Development, 115, 78-93. https://doi.org/10.1016/j.worlddev.2018.10.009

Sweet, C., \& Maggio, D. (2015). Do Stronger Intellectual Property Rights Increase Innovation? World Development, 66, 665-677. https://doi.org/10.1016/j.worlddev.2014.08.025

\section{Notas}

* Artículo de investigación.

1 https://www.epo.org/searching-for-patents/business/patstat.html

2 El Pacto Andino fue formado inicialmente por Bolivia, Colombia, Chile, Ecuador y Perú. Chile se retiró en 1976. En 1973, Venezuela ingresó, pero se retiró en 2006. A partir de 1996 comenzó a llamarse Comunidad Andina.

3 La Asociación Latinoamericana de Libre Comercio -ALALC- fue un organismo regional latinoamericano existente entre 1960 y 1980, creado por el Tratado de Montevideo. Los países firmantes -Argentina, Bolivia, Brasil, Chile, Colombia, Ecuador, México, Paraguay, Perú, Uruguay y Venezuela-, se comprometían a crear una zona de libre comercio. La ALALC fue posteriormente sustituida por Asociación Latinoamericana de Integración -ALADI-, a la cual se unieron Cuba y Panamá.

4 Ver el Acuerdo de Cartagena: http://www.cancilleria.gov.co/sites/default/files/acuerdo-cartagena-decision-563.pdf.

5 Ver http://www.wipo.int/ $/$ wipolex/es/text.jsp?file_id=224049.

6 Estos acuerdos fueron el resultado de un largo proceso de negociaciones de casi 10 años (1985-1995) que se conocen como la Ronda Uruguay firmados el 15 de abril de 1994 y con vigencia a partir del 1 de enero de 1995.

7 Ver http://www.wipo.int/edocs/lexdocs/laws/es/can/can024es.pdf

8 Ver http://www.sice.oas.org/trade/JUNAC/decisiones/DEC344S.asp

9 Ver https://gestion.pe/economia/empresas/colombia-baja-44-precio-medicamento-novartis-cancer-124356, https:// www.swissinfo.ch/spa/-un-gen\%C3\%A9rico-para-glivec-_ong-desaf\%C3\%ADan-a-novartis-en-colombia/41711078 y http://caracol.com.co/radio/2016/04/21/salud/1461275554_063542.html (noviembre de 2017).

\section{Licencia Creative Commons CC BY 4.0}

Para citar este artículo: Campi, M., Dueñas, M. A., \& Zuluaga, J. C. (2020). ¿El fortalecimiento de los derechos de propiedad intelectual estimula la innovación? Un análisis exploratorio de la dinámica de patentamiento por sectores industriales en Colombia, 1980-2010. Cuadernos de Administración, 33(61). ht tps://doi.org/10.11144/Javeriana.cao33.fdpiei 